\title{
Remarkable reversal of ${ }^{13} \mathrm{C}-\mathrm{NMR}$ assignment in $d^{1}, d^{2}$ compared to $d^{8}$ d $^{9}$ acetylacetonate complexes: Analysis and explanation based on Solid-state MAS NMR and computations
}

Anders B. A. Andersen ${ }^{1}$, Ari Pyykkönen ${ }^{2}$, Hans Jørgen Aa. Jensen¹, Vickie McKee ${ }^{1,3}$, Juha Vaara ${ }^{2}$, Ulla Gro Nielsen ${ }^{1, *}$

${ }^{1}$ Department of Physics, Chemistry and Pharmacy, University of Southern Denmark, Campusvej 55, DK-5230 Odense, Denmark

${ }^{2}$ NMR Research Unit, University of Oulu, FI-90014, Finland

${ }^{3}$ School of Chemical Sciences, Dublin City University, Glasnevin, Dublin 9, Ireland.

*Corresponding authors: ugn@sdu.dk +456550 4401 


\section{Graphical Abstract}

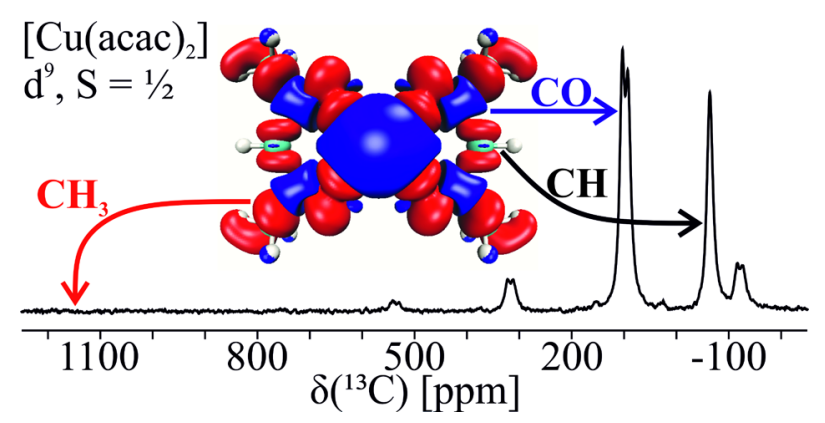

The variation in ${ }^{13} \mathrm{C}$ NMR paramagnetic shifts as a function of d-electron configuration was explained by NMR shielding calculations.

\section{Abstract}

${ }^{13} \mathrm{C}$ solid-state MAS NMR spectra of a series of paramagnetic metal acetylacetonate complexes; $\left[\mathrm{VO}(\operatorname{acac})_{2}\right]\left(\mathrm{d}^{1}, \mathrm{~S}=1 / 2\right),\left[\mathrm{V}(\mathrm{acac})_{3}\right]\left(\mathrm{d}^{2}, \mathrm{~S}=1\right),\left[\mathrm{Ni}(\operatorname{acac})_{2}\left(\mathrm{H}_{2} \mathrm{O}\right)_{2}\right]\left(\mathrm{d}^{8}, \mathrm{~S}=1\right)$, and $\left[\mathrm{Cu}(\operatorname{acac})_{2}\right]\left(\mathrm{d}^{9}\right.$, $\mathrm{S}=1 / 2$ ), were assigned using modern NMR shielding calculations. This provided a reliable assignment of the chemical shifts and a qualitative insight into the hyperfine couplings. Our results show a reversal of the isotropic ${ }^{13} \mathrm{C}$ shifts, $\delta$ iso $\left({ }^{13} \mathrm{C}\right)$, for $\mathrm{CH}_{3}$ and $\mathrm{CO}$ between the $\mathrm{d}^{1}$ and $\mathrm{d}^{2}$ versus the $\mathrm{d}^{8}$ and $\mathrm{d}^{9}$ acetylacetonate complexes. The $\mathrm{CH}_{3}$ shifts change from about $-150 \mathrm{ppm}\left(\mathrm{d}^{1,2}\right)$ to roughly $1000 \mathrm{ppm}\left(\mathrm{d}^{8,9}\right)$, whereas the CO shifts decrease from $800 \mathrm{ppm}$ to about $150 \mathrm{ppm}$ for $\mathrm{d}^{1,2}$ and $\mathrm{d}^{8,9}$, respectively. This was rationalized by comparison of total spin-density plots and computed contact couplings to those corresponding to singly occupied molecular orbitals (SOMOs). This revealed the interplay between spin delocalization of the SOMOs and spin polarization of the lower-energy MOs, influenced by both the molecular symmetry and the $d$-electron configuration. A large positive chemical shift results from spin delocalization and spin polarization acting in the same direction, whereas their cancellation corresponds to a small shift. The $\operatorname{SOMO}(\mathrm{s})$ for the $\mathrm{d}^{8}$ and $\mathrm{d}^{9}$ complexes are $\sigma$-like, implying spin-delocalization on the $\mathrm{CH}_{3}$ and $\mathrm{CO}$ groups of the acac ligand, cancelled only 
for CO by spin polarization. In contrast, the SOMOs of the $\mathrm{d}^{1}$ and $\mathrm{d}^{2}$ systems are $\pi$-like and a large CO-shift results from spin polarization, which accounts for the reversed assignment of $\delta_{\text {iso }}\left({ }^{13} \mathrm{C}\right)$ for $\mathrm{CH}_{3}$ and $\mathrm{CO}$.

\section{Introduction}

The versatile chemistry of non-singlet transition metals render them key components in catalytic, ${ }^{1}$ energy, ${ }^{2}$ and other functionalized materials in both nature and industry. ${ }^{1,3}$ In order to relate the function to the chemistry of such materials, structural information at the atomic level, especially around the paramagnetic center, is required. A common structural characterization method is through scattering techniques, but these approaches are not well suited for materials without long-range order, solid solutions, and 2D materials.

While solid-state NMR (SSNMR) spectroscopy is an appealing technique as it probes the short-range order, the paramagnetic nature, often seen in materials with transition metals, renders NMR spectroscopy inherently difficult. This is due to the hyperfine interaction between the unpaired electrons and the NMR-active nuclei, which greatly complicates the often broad NMR spectra. The resonances from different sites can be distributed over thousands of ppm and each span a large area. Therefore, a robust methodology for the assignment of paramagnetic NMR (pNMR) spectra is needed. First, by the establishment of a reliable computational framework for the calculation of NMR parameters in open-shell systems similar to the DFT methodology used in diamagnetic solids ${ }^{4}$ and, ultimately, by empirical correlations similar to the well-known ${ }^{1} \mathrm{H}$ and ${ }^{13} \mathrm{C}$ NMR shift predictions in organic molecules. Experimentally, acquisition of high-resolution spectra of paramagnetic materials has been facilitated by the possibility of fast MAS $(>20 \mathrm{kHz})$ combined with the development of NMR pulse sequences with large excitation band widths and 2D sequences, ${ }^{5,6}$ e.g., transferred-echodouble resonance (TEDOR), ${ }^{7}$ dipolar heteronuclear single-quantum correlation (HSQC), ${ }^{8}$ and dipolar 
intensive nucleus enhanced by polarization transfer (DINEPT), ${ }^{9}$ for increased spectral resolution. The reader is referred to the recent review by Pell, Pintacuda, and $\mathrm{Grey}^{4}$ for a detailed description of pNMR spectroscopy.

Computationally, the classic theory of pNMR shielding and chemical shift is due to Kurland and McGarvey. ${ }^{10}$ Recent advances have rendered quantum-chemical computation of the shifts reliable enough to aid in the assignment, interpretation, and analysis of pNMR shifts. These include the possibilities for first-principles calculations of pseudocontact shifts, ${ }^{11}$ as well as inclusion of the zero-field splitting (ZFS) in systems with more than one unpaired electron, ${ }^{12,13}$ culminating in a modern computational realization of the Kurland-McGarvey theory. ${ }^{14-16}$ This level of theory involves parameterization of the ground-state multiplet of $2 S+1$ states ( $S$ is the electron spin quantum number) in terms of the standard electron paramagnetic resonance (EPR) spin Hamiltonian, which includes the nuclear and electronic spin-Zeeman interactions, the latter with the $g$-tensor $(\boldsymbol{g})$, the ZFS Hamiltonian in the form of $\boldsymbol{S} \cdot \boldsymbol{D} \cdot \boldsymbol{S}$ (where $\boldsymbol{S}$ is the effective spin operator and $\boldsymbol{D}$ the ZFS tensor); and the hyperfine coupling between the NMR nuclei and the unpaired electrons.

The current modus operandi ${ }^{17}$ in practical calculations, which employ this method, features $\boldsymbol{g}$ and $\boldsymbol{D}$ computed ab initio using relativistic multiconfigurational methods, ${ }^{18,19}$ and the fully relativistic, 4-component DFT method ${ }^{20}$ for the critical hyperfine coupling (HFC) interaction. The method allows for a break-down of the calculated shielding in greater detail than the traditional three components: contact, pseudocontact, and chemical (orbital) shift contributions. ${ }^{13}$ This is achieved via expansions of the $g$ - and HFC tensors in orders of $\alpha^{2}$ of the fine-structure constant $\alpha$. The method is currently formally limited to cases with thermally separated ground multiplet (no low-lying excited multiplets) and paramagnetic centers without strong exchange-coupling. Nevertheless, it has been successfully been applied to analyze a number of experimental situations. ${ }^{15,21,22}$ Recently, the method 
was extended to periodic solids ${ }^{23,24}$ and, combined with the long-range point-dipole approximation, it allowed ab initio pNMR calculations of an entire protein. ${ }^{25}$

Important, so-far non-routine developments beyond the Kurland-McGarvey theory level include the pseudospin formulation ${ }^{26,27}$ which is generally applicable, also in the case of strong spin-orbit coupling. In another line of work, ${ }^{28,29}$ the authors abandoned the use of EPR parameters of the ground multiplet and used explicitly computed ground and excited states coupled via ab initio magnetic operators, instead. Comparison with EPR parameter-based methodology revealed very reassuring performance of the latter. ${ }^{29}$

Generally, the combination of experimental NMR and computational studies of paramagnetic materials have focused on the effect of varying the ligands around the single paramagnetic $d$-metal center with an emphasis on assignment of the experimental SSNMR spectra or benchmarking of computational methods using experimental NMR data. ${ }^{4,}$ 30, 31 Moreover, most studies have focused on a single isolated metal center, except for recent studies of a $\mathrm{Cu}$ (II) dimer benzoate complex, $\left[\mathrm{Cu}_{2}\left(\mathrm{C}_{6} \mathrm{H}_{5} \mathrm{CO}_{2}\right){ }_{4} \cdot 2\right.$ (urea) $]$, where the experimental solid-state ${ }^{13} \mathrm{C}$ chemical shifts could be modelled using a thermal average of the diamagnetic singlet ground state and a low-lying excited paramagnetic triplet state. ${ }^{32}$ Very few studies have investigated how the choice of $d$-metal center affects the NMR parameters in the solid state, except for $1^{\text {st }}$ row metallocenes. ${ }^{4,12,13,30,33-36}$ The systematic variations in the paramagnetic shift, observed in both liquid- and solid-state ${ }^{1} \mathrm{H}$ and ${ }^{13} \mathrm{C}$ NMR spectra, could be rationalized based different polarization mechanisms. ${ }^{4,30,35}$

From calculation of EPR parameters, it is well known that spin delocalization, the fact that the direct spin density of the singly occupied molecular orbitals (SOMOs) can extend to the NMR nuclei in the ligands, provides an important contribution to the hyperfine couplings. ${ }^{40}$ Moreover, spin polarization of the formally doubly occupied lower-energy molecular orbitals (MOs) results from the 
different interactions experienced by the spin-up and spin-down electrons with the SOMOs, and can contribute crucially to the total hyperfine interaction, particularly when the direct spin density at the nucleus vanishes, e.g., for symmetry reasons..$^{30,41,42}$ A similar effect has been observed in NMR studies. Thus, calculated spin-density plots have been used to obtain a qualitative understanding of the sign and magnitude of the paramagnetic NMR shifts observed experimentally., ${ }^{42,37-39}$ Whether the two mechanisms are accessed in the computations, depends on the computational framework used. In single-determinantal restricted open-shell calculations, the doubly occupied MOs have similar spatial parts for both spin-up and spin-down electrons, and spin polarization contributions cannot be obtained. Instead, when using an unrestricted formalism as in the present paper, the different interactions experienced by the two spin populations are accommodated, allowing both spindelocalization and spin-polarization mechanisms to affect the calculated hyperfine couplings. To separate the two effects, either additional restricted calculations or MO analysis of the direct spin density contribution should be performed, to extract the contribution of spin polarization. We follow the latter approach here.

For example, NMR shifts and spin densities obtained from basic DFT calculations of Jahn-Teller distorted [Mn(acac)3] polymorphs allowed for assignment of the ${ }^{13} \mathrm{C}$ and ${ }^{1} \mathrm{H}$ MAS NMR, as well as probing effects of structural modification. ${ }^{39}$ However, only isotropic shifts were reported, and the Fermi contact shift was the only contribution included in the calculations. Marek and coworkers have extensively studied $4 d$ and $5 d$ metal-organic complexes to explain the observed pNMR shifts based on electronic structure..$^{37,38,43,44}$ Recently, by variation of both ligand and metal oxidation states, the effects on the NMR shifts could be explained based on the contribution of the different SOMOs and total spin density plots. ${ }^{38}$

The objective of the present work is to investigate the effect of the $3 d$-electron configuration in a series of structurally related acetyl acetonate (acac) complexes with different 
transition metal ions depicted in Fig. 1: bis(acetylacetonato)vanadium(IV) oxide ([VO(acac)2]), tris(acetylacetonato)vanadium(III) ([V(acac)3]), tris(acetylacetonato)cobalt(III) ([Co(acac)3]), transbis(acetylacetonato)diaquanickel(II) ([Ni(acac) $\left.\left.)_{2}\left(\mathrm{H}_{2} \mathrm{O}\right)_{2}\right]\right), \quad$ and bis(acetylacetonato)copper(II) $\left(\left[\mathrm{Cu}(\mathrm{acac})_{2}\right]\right)$ using a combined computational and experimental approach, where the total shift tensor is obtained. These acac complexes were chosen because the three types of carbons in the acac-ligand had distinct paramagnetic shift tensors in our previous studies of $\left[\mathrm{Ni}(\mathrm{II})(\mathrm{acac})_{2} \mathrm{~L}_{2}\right] .{ }^{22,45} \mathrm{In}$ particular, the assignment of the ${ }^{13} \mathrm{C}-\mathrm{NMR}$ shifts of $\mathrm{CH}_{3}$ and $\mathrm{CO}$ groups ${ }^{45}$ had to be counter-intuitively reversed based on quantum-chemical calculations ${ }^{22}$ employing the recipe of Ref. ${ }^{16}$. Pritchard and Autschbach ${ }^{46}$ investigated computationally the $\mathrm{M}(\mathrm{acac})_{3}[\mathrm{M}=\mathrm{Cr}(\mathrm{III}), \mathrm{Fe}(\mathrm{III})$ and $\mathrm{Ru}(\mathrm{III})]$ systems and noted a related change of sign for the methyl group ${ }^{13} \mathrm{C}$ signals. Here, we investigate a systematic variation of the assignments in a selection of $3 d$ metals involving $\mathrm{d}^{1}, \mathrm{~d}^{2}, \mathrm{~d}^{8}$, and $\mathrm{d}^{9}$ acac complexes. Not all ${ }^{13} \mathrm{C}$ resonances were observed in the experimental ${ }^{13} \mathrm{C}$ MAS NMR spectra due to fast paramagnetic relaxation enhancement (PRE), which also prevented assignment using empirical methods. The assignment of the ${ }^{13} \mathrm{C}$ MAS NMR parameters is mainly linked to the $d$-electron configuration and is explained by reversal of the weights of the total spin densities at the carbon centers in the early versus late $3 d$ complexes studied. Our study shows that spin polarization strengthens or counteracts the direct spin delocalization contributions to ${ }^{13} \mathrm{C}$ hyperfine interactions in the $\mathrm{CH}_{3}$ and $\mathrm{CO}$ groups in the early and late $3^{\text {rd }}$ row complexes, respectively. The contributions from the distinct mechanisms ${ }^{13}$ to the total shielding tensor are also investigated.

\section{Experimental and Computational Methods}

\section{Chemicals.}


$\left[\mathrm{VO}(\mathrm{acac})_{2}\right]$ and $\left[\mathrm{Co}(\mathrm{acac})_{3}\right]$, which were used without further purification, and [V(acac)3] were bought from Sigma Aldrich. [V(acac)3] $(0.9843 \mathrm{~g})$ was recrystallized in degassed dry tetrahydrofuran (THF) under $\mathrm{N}_{2}$-atmosphere ${ }^{47}$ by boiling the $\mathrm{V}(\mathrm{acac})_{3} / \mathrm{THF}$ solution and then cooling to room temperature. The solution was further cooled in a freezer $\left(-18^{\circ} \mathrm{C}\right)$ for a day yielding dark red crystals. The crystals were washed with cold $\left(-18^{\circ} \mathrm{C}\right)$ dry THF and dried under reduced pressure. $\left[\mathrm{Cu}(\mathrm{acac})_{2}\right]$ was prepared ${ }^{48}$ by drop-wise addition of a solution of $5 \mathrm{~cm}^{3}$ (ca. $0.05 \mathrm{~mol}$ ) of acetylacetone in $10 \mathrm{~cm}^{3}$ methanol to a solution of $4 \mathrm{~g}$ (ca. $0.025 \mathrm{~mol}$ ) copper(II) chloride dihydrate $\left(\mathrm{CuCl}_{2} \cdot 2 \mathrm{H}_{2} \mathrm{O}\right)$ in $25 \mathrm{~cm}^{3}$ of distilled water, contained in a $250 \mathrm{~cm}^{3}$ conical flask under constant stirring. Sodium acetate $(6.8 \mathrm{~g})$ in $15 \mathrm{~cm}^{3}$ distilled water was added over a period of $5 \mathrm{~min}$ and the mixture was heated at $80{ }^{\circ} \mathrm{C}$ for 15 min with rapid stirring. It was cooled to room temperature and then in an ice water bath. The blue-grey product was filtered and washed with cold distilled water and dried in an oven at $110^{\circ} \mathrm{C}$.

\section{Characterization.}

Powder X-ray diffraction (PXRD) diffractograms were recorded with a Rigaku Miniflex 600 X-Ray diffractometer using $\mathrm{Cu} \mathrm{K \alpha}$ radiation (1.5405 Å). Single crystal X-ray diffraction for $\left[\mathrm{V}(\mathrm{acac})_{3}\right]$ were collected at 100(1) K on a Synergy, Dualflex, AtlasS2 diffractometer using $\mathrm{Cu} K \alpha$ radiation $(\lambda=1.54184 \AA)$ and the CrysAlis PRO suite (ver. 1.171.40.29a). ${ }^{49}$ Using SHELXLE $^{50}$ and Olex ${ }^{51}$ the structure was solved by dual space methods (SHELXT ${ }^{52}$ ) and refined on $F^{2}$ using all the reflections (SHELXL-2018/3). ${ }^{53}$ Further details on single crystal XRD on $\left[\mathrm{V}(\mathrm{acac})_{3}\right]$ are included in the Electronic Supplementary Information (ESI). The PXRD diffractograms were checked with the reported crystal structures. ${ }^{47,}$ 54-56 Elemental analyses: [VO(acac) 2$](\mathrm{MW}=348.3): \mathrm{C}, 51.73 ; \mathrm{H}, 6.08$. Found: $\mathrm{C}, 45.72(10) ; \mathrm{H}, 5.64(7)$. [V(acac) 3$](\mathrm{MW}=$ 265.2): C, 45.30; H, 5.32. Found: C, 51.81(6); H, 6.24(1). [Co(acac)3] (MW = 257.2): C, 50.57; H, 
5.94. Found: C, 50.84(3); H, 6.32(1). [Cu(acac)2] ( $\mathrm{MW}=261.8)$ : C, 45.88; H, 5.39. Found: $\mathrm{C}$, 45.67(4); H, 5.40(1).

Solid-state NMR spectroscopy.

Solid-state ${ }^{13} \mathrm{C}$ MAS-NMR spectra were recorded on a JEOL RESONANCE JNMECZ500R spectrometer equipped with an $11.7 \mathrm{~T}$ Oxford magnet, using a $3.2 \mathrm{~mm}$ double-resonance MAS probe (13-18 kHz spinning speeds, ambient temperatures), and on an Agilent INOVA spectrometer at $14.1 \mathrm{~T}$ using a $1.6 \mathrm{~mm}$ triple-resonance MAS probe (19-40 kHz spinning speeds) and with the temperature of the gas set to $30{ }^{\circ} \mathrm{C}$. The ${ }^{13} \mathrm{C}$ chemical shifts, $\delta$ iso $\left({ }^{13} \mathrm{C}\right)$, were referenced to TMS using adamantane $\left(\delta_{\text {iso }}\left({ }^{13} \mathrm{C}\right)=37.77 \mathrm{ppm}\right)$ as a secondary reference. ${ }^{57}$ The magic angle was set by minimizing the width of spinning sidebands of either ${ }^{79} \mathrm{Br}$ or ${ }^{23} \mathrm{Na}$ in $\mathrm{KBr}$ and $\mathrm{NaNO}_{3}$, respectively. Single-pulse ${ }^{13} \mathrm{C}$ and ${ }^{13} \mathrm{C}$ rotor-synchronized Hahn-Echo $\left(90^{\circ}-\tau-180^{\circ}-\tau\right.$-acquisition) NMR spectra were recorded with three to eight different spinning speeds, between 15000 to 300000 scans, $\tau$ set to one rotor period, and a recycle delay between $0.5 \mathrm{~s}$ to $1.5 \mathrm{~s}$. Additionally, Inversion-Recovery ${ }^{13} \mathrm{C}$ NMR spectra $\left(180^{\circ}-\tau-90^{\circ}\right.$-acquisition) with different carrier settings (near the isotropic resonances) were obtained for $\left[\mathrm{VO}(\mathrm{acac})_{2}\right],\left[\mathrm{V}(\mathrm{acac})_{3}\right]$, and $\left[\mathrm{Cu}(\mathrm{acac})_{2}\right] .{ }^{13} \mathrm{C}$ values for $\left[\mathrm{Co}(\mathrm{acac})_{3}\right]$, which was used as a diamagnetic model compound, were obtained by Cross Polarization (CP) and CrossPolarization Inversion-Recovery (CP-180 $-\tau-90^{\circ}$-acquisition). The data was processed using MestReNova (ver. 12.0.3). Microsoft Excel and Python 3 script were used for processing the inversion-recovery data, the script is provided in the ESI (S1). The $\mathrm{T}_{1}$ values are reported as an average of the two processing methods. The total ${ }^{13} \mathrm{C}$ chemical shift anisotropy (CSA) and deconvolution of overlapping sites were determined using ssNake (ver. 1.1). ${ }^{58}$ The total CSA tensor is given using the Haeberlen convention ${ }^{57}$ with isotropic chemical shift value defined as 


$$
\delta_{i s o}=\frac{1}{3}\left(\delta_{x x}+\delta_{y y}+\delta_{z z}\right)
$$

with the principal components ordered according to:

$$
\left|\delta_{z z}-\delta_{i s o}\right| \geq\left|\delta_{x x}-\delta_{i s o}\right| \geq\left|\delta_{y y}-\delta_{i s o}\right|
$$

the reduced anisotropy

$$
\Delta=\delta_{z z}-\delta_{i s o}
$$

and the asymmetry

$$
\eta=\frac{\delta_{y y}-\delta_{x x}}{\Delta}
$$

where $0 \leq \eta \leq 1$. Please note that $x, y$, and $z$ indices in the Haeberlen convention refer to atomic coordinates of the nuclei in question and not the molecular coordinates. Furthermore, the total CSA tensor is reported as an average of two simulations at different spinning speeds for each metal complex, except for [VO(acac)2], where only one spinning speed was used due to poor data quality.

\section{Computational.}

The theoretical prediction of pNMR shieldings was based on the modern form of the Kurland-McGarvey theory, ${ }^{10,14,16}$ in which the magnetic interactions are parameterized in the ground multiplet by EPR parameters (hyperfine couplings, zero-field splitting and g-tensor). The resulting formula for the Cartesian $\varepsilon \tau$-component of the pNMR shielding tensor for nucleus $K$ is

$$
\sigma_{K, \varepsilon \tau}=\sigma_{K, \varepsilon \tau}^{\mathrm{orb}}-\frac{\mu_{B}}{\gamma_{K} \hbar k T} \sum_{a b} g_{\varepsilon a}\left\langle S_{a} S_{b}\right\rangle A_{K, b \tau}
$$

where $\sigma_{K, \varepsilon \tau}^{\text {orb }}, g_{\varepsilon a}$ and $A_{K, b \tau}$ are the Cartesian components of the orbital shielding tensor, the $g$-tensor and the hyperfine coupling tensor, respectively. The quantities $\mu_{B}, \gamma_{K}, k$ and $T$ are the Bohr magneton, 
gyromagnetic ratio of nucleus $K$, Boltzmann constant and absolute temperature, respectively. The dyadic $\langle\boldsymbol{S S}\rangle$ is expressed in terms of the effective spin operators $\boldsymbol{S}$,

$$
\left\langle S_{a} S_{b}\right\rangle=\frac{\sum_{n m} Q_{n m}\left\langle n\left|S_{a}\right| m\right\rangle\left\langle m\left|S_{b}\right| n\right\rangle}{\sum_{n} \exp \left(-E_{n} / k T\right)}
$$

where $Q_{n m}$ are

$$
Q_{n m}= \begin{cases}\exp \left(-E_{n} / k T\right), & E_{n}=E_{m} \\ -\frac{k T}{E_{m}-E_{n}}\left[\exp \left(-E_{m} / k T\right)-\exp \left(-E_{n} / k T\right)\right], & E_{n} \neq E_{m}\end{cases}
$$

and $|n\rangle, E_{n}$ are the eigenfunctions and -values of the ZFS Hamiltonian $\boldsymbol{S} \cdot \boldsymbol{D} \cdot \boldsymbol{S}$ at the limit of a vanishing external magnetic field.

The geometry optimization of each system was carried out using unrestricted KohnSham (UKS) DFT with the standard PBE0 functional ${ }^{59}$ with $25 \%$ exact Hartree-Fock exchange, as well as the DFT-D3 BJ dispersion correction. ${ }^{60,61}$ The def2-TZVP basis set ${ }^{62}$ was employed for light ligand atoms, and the Stuttgart-type scalar relativistic effective core potential ECP10MDF ${ }^{63}$ was used for the metal centers, along with the appropriate $6 \mathrm{~s} 5 \mathrm{p} 3 \mathrm{~d} 2 \mathrm{f} 1 \mathrm{~g} / 8 \mathrm{~s} 7 \mathrm{p} 6 \mathrm{~d} 2 \mathrm{f} 1 \mathrm{~g}$ (contracted/uncontracted) valence basis set. The TURBOMOLE software (ver. 7.2) ${ }^{64}$ was utilized in this phase. The optimized coordinates of the systems are given in Tables S1 to S5.

The EPR parameters were computed following the previously reported approach, ${ }^{16,17}$ which has been found to be efficient for these systems. ${ }^{17,21,22}$ The $\boldsymbol{D}$ and $\boldsymbol{g}$ tensors were calculated using the ORCA program ${ }^{65}$ at the NEVPT2 ${ }^{66-68}$ level of theory, based on a state-averaged CAS $(n, 5)$ $\mathrm{CASSCF}^{69}$ wavefunction correlating $n d$-electrons of the metal center in the five metal $3 d$-orbitals. The second-order Douglas-Kroll-Hess method $(\mathrm{DKH} 2)^{70,} 71$ was used to approximate scalar relativistic effects, and spin-orbit effects (using the picture-changed spin-orbit operator) were included via the quasidegenerate perturbation theory (QDPT) method. ${ }^{18,19}$ Only the spin-orbit 
contribution to the ZFS was considered, as the spin-spin contribution can be expected to be small in comparison. A "locally dense" basis set was employed, in which the DKH-def2-TZVP basis set" was used on the metal atom and ligand atoms directly bonded to it, whereas the DKH-def2-SVP basis set was used on other atoms. The calculated principal components of the $g$-tensor and the $D$ and $E$ parameters of the ZFS tensor are listed in Table S6.

Spin polarization of core electrons must be included in calculation of the HFC is included to obtain reasonable results. Such calculations were carried out with the ReSpect program package (ver. 3.4.2) ${ }^{73}$ using the unrestricted Kohn-Sham (UKS)-based, fully relativistic, fourcomponent mDKS method ${ }^{20}$ along with a decontracted DKH-def2-TZVP basis set on ligand atoms, and the uncontracted Dyall-VTZ basis set on the metal center, as well as the PBE0 functional. Within this method, both scalar relativistic and spin-orbit effects are considered variationally. The choice of exact exchange admixture in the DFT functional is important. The PBE0 functional with 25 percent exact exchange has been found to produce qualitatively correct results.

The orbital shielding term, which is less critical than the EPR parameters, was calculated at the UKS/PBE0 level of theory employing the DKH-def2-TZVP basis set. Here, the Gaussian 09 software ${ }^{74}$ was used. The physical contributions to the calculated shielding tensors were analysed as detailed in Table S7.

The ${ }^{13} \mathrm{C}$ NMR shielding constant $188.4 \mathrm{ppm}$ of the diamagnetic, closed-shell reference compound tetramethylsilane (TMS) was computed also with the Gaussian 09 program at the PBE0/DKH-def2-TZVP level corresponding to the orbital shielding of the present transition metal complexes. The computational results are averaged over the experimentally equivalent nuclei and given as shielding, $\sigma$, which must be converted into chemical shift values by

$$
\delta=\sigma_{r e f}-\sigma
$$


where $\sigma_{\text {ref }}$ is the calculated shielding of the TMS reference.

\section{Results}

First, the experimental ${ }^{13} \mathrm{C}$ MAS NMR spectrum of $\left[\mathrm{Cu}(\mathrm{acac})_{2}\right]$ will be analyzed in detail, before briefly discussing the experimental spectra for $\left[\mathrm{VO}(\mathrm{acac})_{2}\right]$ and $\left[\mathrm{V}(\mathrm{acac})_{3}\right]$. Experimental ${ }^{13} \mathrm{C}$ SSNMR data for $\left[\mathrm{Ni}(\mathrm{acac})_{2}\left(\mathrm{H}_{2} \mathrm{O}\right)_{2}\right]$ were reported earlier. ${ }^{22}$ Then the experimental results will be compared with the computational results, followed by discussion of the combined observations.

Assignment of the ${ }^{13} \mathrm{C} M A S$ NMR spectra of $\left.\left[\mathrm{Cu}(\mathrm{acac})_{2}\right], \quad V O(a c a c)_{2}\right], \quad\left[V(a c a c)_{3}\right]$, and $\left[\mathrm{Ni}(\mathrm{acac})_{2}\left(\mathrm{H}_{2} \mathrm{O}\right)_{2}\right]$.

The ${ }^{13} \mathrm{C}$ MAS NMR spectrum of $\left[\mathrm{Cu}(\mathrm{acac})_{2}\right]$ contain three sites at $\delta_{\text {iso }}\left({ }^{13} \mathrm{C}\right)=-67(7)$, 92(5), and 102(5) ppm (Fig. 2) and were identified by comparison of ${ }^{13} \mathrm{C}$ MAS NMR spectra recorded with different spinning speeds. The crystal structure contains half a molecule, i.e., one acac-ligand, in the asymmetric unit. ${ }^{56}$ Thus, five ${ }^{13} \mathrm{C}$ resonances are expected: $\mathrm{CH}_{3}, \mathrm{C}^{\prime} \mathrm{H}_{3}, \mathrm{CO}, \mathrm{C}^{\prime} \mathrm{O}$, and $\mathrm{CH}$, but only three resonances were observed experimentally. Hence, either there is spectral overlap due to very similar chemical environments of $\mathrm{C}$ and $\mathrm{C}$ ' or two signals are missing from the experimental spectrum due to PRE. ${ }^{4}$

Based on the computational shifts and shift anisotropies, the resonance at $\delta_{\text {iso }}\left({ }^{13} \mathrm{C}\right)$ $=-67(7)$ ppm (computations: $-44 \mathrm{ppm})$ is assigned to methine $(\mathrm{CH})$, whereas the two resonances at 92(5) ppm and 102(5) ppm (computations: $149 \mathrm{ppm}$ ) belong to the carbonyls (CO). We note that the calculations are performed in vacuo for the optimized symmetric molecular structure and, therefore, only a single resonance is obtained per functional group. The methyl groups $\left(\mathrm{CH}_{3}\right)$, which the 
computations predict to have the isotropic shift $\delta_{\text {iso }}\left({ }^{13} \mathrm{C}\right) \approx 1153 \mathrm{ppm}$, are not observed due to PRE. A ${ }^{13} \mathrm{C}$ MAS NMR spectrum was recorded with $80 \mathrm{kHz}$ spinning (not shown) to increase the resolution, but also contained only three sites. The resonance at $-67 \mathrm{ppm}$ is assigned to $\mathrm{CH}$ based on the multiplicity ( $1 \mathrm{CH}$ group vs $2 \mathrm{CH}_{3}$ and $2 \mathrm{CO}$ in the asymmetric unit). Further information is obtained from the anistropic parts of the total shielding tensor, i.e., the total (reduced) anisotropy, $\Delta$, and asymmetry, $\eta$ (Table 1), which were determined from fitting simulated spectra to the experimental ${ }^{13} \mathrm{C}$ MAS NMR spectra (Fig. S1, see Table S8 for computationally obtained principal values of the shielding tensors). The total shift anisotropies $(\Delta)$ are larger (and oppositely signed) for the two resonances at 92 and $102 \mathrm{ppm}$, in line with the signals originating from carbons closer to the paramagnetic center than the $\mathrm{CH}$ group, i.e., the two $\mathrm{CO}$ groups. It should be noted that $\Delta$ contains contributions from both the orbital (chemical shift anisotropy/shielding) and hyperfine terms for paramagnetic compounds.

The $T_{1}$ values of $3.2(13) \mathrm{ms}, 0.5(1) \mathrm{ms}$, and $0.6(1) \mathrm{ms}$ were determined for the resonances at $\delta_{\text {iso }}\left({ }^{13} \mathrm{C}\right) \approx-67 \mathrm{ppm}, 92 \mathrm{ppm}$, and $102 \mathrm{ppm}$, respectively, c.f., Table 1 . The two resonances at $102 \mathrm{ppm}$ and $92 \mathrm{ppm}$ have similar $\delta_{\text {iso }}\left({ }^{13} \mathrm{C}\right)$ and $T_{1}$ and must again originate from the same functional group, i.e., either $\mathrm{CO}$ or $\mathrm{CH}_{3}$. To a crude first approximation, the relaxation rate decreases with the distance to the paramagnetic ion in the molecule, assuming that the unpaired electron spin density is localized on the $\mathrm{Cu}$ (II) ion and that the pseudocontact interaction is the dominant contribution to the hyperfine coupling (Table S9 contain the physical contributions to the calculated ${ }^{13} \mathrm{C}$ shielding constants). Hence, $T_{1}\left(\mathrm{CH}_{3}\right)>T_{1}(\mathrm{CH})>T_{1}(\mathrm{CO})$ could be expected, and the two resonances at $\delta_{\text {iso }}\left({ }^{13} \mathrm{C}\right) \approx 92 \mathrm{ppm}$ and $102 \mathrm{ppm}$ would be assigned to $\mathrm{CH}_{3}$ and the two missing resonances must then be from the carbonyls, $\mathrm{CO}$, as they are closest to the paramagnetic center. However, the computational results clearly show this to be a non-valid approximation, as the largest spin density is on the methyl groups (vide infra). 
The $\mathrm{d}^{8}$ complex $\left[\mathrm{Ni}(\operatorname{acac})_{2}\left(\mathrm{H}_{2} \mathrm{O}\right)_{2}\right]$ has one less $d$-electron than $\left[\mathrm{Cu}(\mathrm{acac})_{2}\right]$. Table 1 shows the ${ }^{13} \mathrm{C}$ MAS NMR resonance from the methyl groups to have the largest paramagnetic shift $\left(\delta_{\text {iso }}\left({ }^{13} \mathrm{C}\right) \approx 796(20) \mathrm{ppm}\right.$ and $\left.891(20) \mathrm{ppm}\right),{ }^{22}$ which is supported by the computational results. For $\left[\mathrm{Ni}(\mathrm{acac})_{2}\left(\mathrm{H}_{2} \mathrm{O}\right)_{2}\right]$, the methyl groups were indeed significantly broader than the $\mathrm{CH}$ and $\mathrm{CO}$ groups. The reader is referred to previous studies ${ }^{22,45}$ for a detailed discussion of the experimental ${ }^{13} \mathrm{C}$ MAS NMR data for $\left[\mathrm{Ni}(\mathrm{acac})_{2}\left(\mathrm{H}_{2} \mathrm{O}\right)_{2}\right]$.

The ${ }^{13} \mathrm{C}$ MAS NMR spectra of $\left[\mathrm{VO}(\mathrm{acac})_{2}\right]$ and $\left[\mathrm{V}(\mathrm{acac})_{3}\right]$ (Fig. 2) were analyzed in a similar way and the results are summarized in Table 1. Ten ${ }^{13} \mathrm{C}$ resonances are predicted for $\left[\mathrm{VO}(\mathrm{acac})_{2}\right],{ }^{54}$ but only six were observed in the spectra at $\delta_{\text {iso }}\left({ }^{13} \mathrm{C}\right)=$ 61(4), -56(4) ppm, -52(4) ppm, -29(4) ppm, 242(1) ppm, and 266(10) ppm, implying spectral overlap and/or missing resonances due fast PRE. The computations provide unambiguous assignment of the four first and two last signals to $\mathrm{CH}_{3}$ (computations: $-80 \mathrm{ppm}$ ) and $\mathrm{CH}$ (264 ppm) groups, respectively. The calculations suggest a very large spin density on the carbonyl (predicted $\delta_{\text {iso }}=$ $852 \mathrm{ppm})$, which can explain the unobserved resonances similar to the $\left[\mathrm{Cu}(\mathrm{acac})_{2}\right]$ complex. $\mathrm{A}^{13} \mathrm{C}$ MAS NMR spectrum recorded using $80 \mathrm{kHz}$ spinning speed (not shown) did not lead to observation of the missing $\mathrm{CO}$ resonances. The assignment is supported by the total shift anisotropy, which is significantly larger $(\Delta \approx 200-300 \mathrm{ppm})$ than for the other four resonances $(\Delta \approx 70 \mathrm{ppm})$, in agreement with the methyl group being furthest away from the paramagnetic center. Again, the computational results match well with the experimental results.

For the $\left[\mathrm{V}(\mathrm{acac})_{3}\right]$, a number of crystalline polymorphs of are known; ${ }^{47}$ with the phase observed apparently dependent on the crystallisation solvent and the data collection temperature. The current example appears to be the same as that reported by Sanz-Ruiz et al ${ }^{55}$ at room temperature, although no twinning was reported in that case and the current refinement is significantly better (see $\mathrm{S} 2$, Tables S10 and S11). All fifteen ${ }^{13} \mathrm{C}$ resonances for $[\mathrm{V}(\mathrm{acac}) 3]$, as predicted from the crystal 
structure, were observed and the results are reported in Table 1 and fitted spectra are shown in Fig. $\mathrm{S} 1$. The signals fall in three groups with distinct isotropic shifts: around $-200 \mathrm{ppm}$ (six resonances), $80 \mathrm{ppm}$ (three resonances), and 950 to $1100 \mathrm{ppm}$ (six resonances), and based on the total anisotropy of about 100 to $150 \mathrm{ppm}, 250 \mathrm{ppm}$, and $-350 \mathrm{ppm}$, the resonances are assigned to $\mathrm{CH}_{3}, \mathrm{CH}$, and $\mathrm{CO}$, respectively. This is consistent with earlier ${ }^{2} \mathrm{H}$ and ${ }^{13} \mathrm{C}$ NMR studies on $\left[\mathrm{V}(\mathrm{acac})_{3}\right]$ by Liu $e$ a $a l^{75}$ and Ishii et al, ${ }^{5}$ respectively. Additionally, this is in excellent agreement with the computational results, which produce isotropic shifts (shift anisotropies) of -240(64) ppm, 8(369) ppm, and 1015(-431) ppm for $\mathrm{CH}_{3}, \mathrm{CH}$ and $\mathrm{CO}$, respectively. Some of the $T_{1}$ 's for both [ $\left.\mathrm{VO}(\mathrm{acac})_{2}\right]$ and $\left[\mathrm{V}(\mathrm{acac})_{3}\right]$ could only be determined as the average values of the ${ }^{13} \mathrm{C}$ due to spectral overlap, but the overall trend supports the above assignment albeit the $\mathrm{CH}$ and $\mathrm{CH}_{3}$ groups have quite similar $\mathrm{T}_{1}$ values in each case, $c . f$., Table 1.

\section{Discussion: Reversed assignment in early and late transition-metal complexes}

A clear correlation is seen between the sign and relative magnitude for most calculated and experimental paramagnetic shifts for all the observable resonances, as illustrated in Fig. 3a. We note that two group of resonances were not observed experimentally, $\mathrm{CO}$ in $\left[\mathrm{VO}(\mathrm{acac})_{2}\right]$ and $\mathrm{CH}_{3}$ in $\left[\mathrm{Cu}(\mathrm{acac})_{2}\right]$ (vide supra). From Fig. 3 one of the key observations of our study can be made: there is a trend in the order of the chemical shifts and signal assignment of the different functional groups as a dependence on the number of $d$-electrons. The $\mathrm{CH}_{3}$ shifts go from negative values for the $\mathrm{d}^{1}$ and $\mathrm{d}^{2}$ systems to large positive values for the $\mathrm{d}^{8}$ and $\mathrm{d}^{9}$ systems, whereas the $\mathrm{CO}$ shifts show the opposite trend, i.e., go from large positive values for the $\mathrm{d}^{1}$ and $\mathrm{d}^{2}$ systems to relatively small and positive values for the $\mathrm{d}^{8}$ and $\mathrm{d}^{9}$ systems. It is noteworthy that a change of sign of the $\mathrm{CH}_{3}$ shift has earlier been reported for the $\mathrm{d}^{3} \mathrm{Cr}(\mathrm{acac})_{3}$ and the $\mathrm{d}^{5} \mathrm{Fe}(\mathrm{acac})_{3}$ systems, with values $-130 \mathrm{ppm}$ and $279 \mathrm{ppm}$, 
respectively. ${ }^{76}$ These values appear to be consistent with our data for the present $d^{1}, d^{2}, d^{8}$ and $d^{9}$ systems. The shift changes for the $\mathrm{CH}$ groups are less drastic when compared to the $\mathrm{CH}_{3}$ and $\mathrm{CO}$, when going from $\mathrm{d}^{1}$ and $\mathrm{d}^{2}$ to $\mathrm{d}^{8}$ and $\mathrm{d}^{9}$, c.f., Fig. 4.

Table S9 lists the physical contributions to the isotropic shielding constant in terms of the break-down ${ }^{13}$ according to powers in $\alpha^{2}$. The contributions are also visualized in Fig. 5 for the different systems. The main contribution to the calculated shielding for all the present systems is the term 1 (Fig. 5), the contact coupling (i.e., terms arising from the isotropic part of the total hyperfine interaction (Table S7)) and, in particular, hardly any contribution from the pseudocontact coupling (terms involving the anisotropic but symmetric, rank-2, part of the hyperfine coupling tensor) is observed. The dominating role of the contact contribution has previously been reported for $\mathrm{M}(\mathrm{acac})_{3}$ with $\mathrm{M}=\mathrm{Cr}(\mathrm{III}), \mathrm{Fe}(\mathrm{III})$ and $\mathrm{Ru}(\mathrm{III}) .{ }^{46}$ The good qualitative agreement between the experimental and calculated shifts validates our theoretical approach. Thus, we can conclude that the observed trends for the paramagnetic shifts can be qualitatively explained by the contact interaction alone, as the other contributions, e.g., the orbital and pseudocontact mechanisms only yield much smaller contributions (Figs. 4 and 5; Table 1). We focus on the contact term to provide a tangible explanation of the observed trends, in particular the reversed assignment of $\mathrm{CH}_{3}$ and $\mathrm{CO}$ signals between the $\mathrm{d}^{1,2}$ and $d^{8,9}$ systems, by inspection of the spin density distribution of each system. Fig. $3 b$ illustrates the calculated total spin densities, where regions of positive spin density correspond to a negative contact contribution to the shielding constant (positive shift) of the ${ }^{13} \mathrm{C}$ nuclei and vice versa. As the plots are based on the present unrestricted DFT calculations, they contain both the spin-delocalization and the spin-polarization contributions. The two mechanism can be distinguished by inspection of the plots of the SOMOs, from which only the spin-delocalization can be inferred. The present $\mathrm{d}^{1}$ and $\mathrm{d}^{9}$ systems have one SOMO, whereas there are two for two the $\mathrm{d}^{2}$ and $\mathrm{d}^{8}$ systems (Fig. S3). 
The calculated SOMOs (Fig. S3) for $\left[\mathrm{Ni}(\mathrm{acac})_{2}\left(\mathrm{H}_{2} \mathrm{O}\right)_{2}\right]\left(\mathrm{d}^{8}, \mathrm{~S}=1\right)$ and $\left[\mathrm{Cu}(\mathrm{acac})_{2}\right]\left(\mathrm{d}^{9}\right.$, $\mathrm{S}=1 / 2$ ) are $\sigma$-like and distributed over the $\mathrm{CH}_{3}$ and $\mathrm{CO}$ functional groups, especially the SOMO1 for $\left[\mathrm{Ni}(\mathrm{acac})_{2}\left(\mathrm{H}_{2} \mathrm{O}\right)_{2}\right]$. This is in good agreement with ligand-field theory for square-planar complexes, which predicts formation of SOMOs by mixing of ligand $\sigma$-orbitals with either $d_{x y}$ or $d_{x^{2}-y^{2}}$ orbitals due to symmetry arguments. The distribution of the $\sigma$-like SOMO for both systems accounts for a positive spin-delocalization contribution to the $\mathrm{HFC}$ of the $\mathrm{CH}_{3}$ and $\mathrm{CO}$ groups (Fig. S3). Additionally, negative spin density is observed on $\mathrm{CO}$ and $\mathrm{CH}$ in the total spin-density plots (Fig. 3b), which is indicative of spin-polarization contributions. Thus, the total shieldings of the functional groups contain contributions from both delocalization of SOMOs (positive, $\mathrm{CH}_{3}$ and $\mathrm{CO}$ ) and spin polarization (negative, $\mathrm{CO}$ and $\mathrm{CH}$ ). This gives the large positive ${ }^{13} \mathrm{C}$ shifts for the $\mathrm{CH}_{3}$ groups and relatively small paramagnetic shift changes for both $\mathrm{CO}$ and $\mathrm{CH}$, as compared to the diamagnetic counterpart, $\left[\mathrm{Co}(\mathrm{acac})_{3}\right]$.

The calculated SOMOs for $\left[\mathrm{VO}(\mathrm{acac})_{2}\right]\left(\mathrm{d}^{1}, \mathrm{~S}=1 / 2\right)$ and $\left[\mathrm{V}(\mathrm{acac})_{3}\right]\left(\mathrm{d}^{2}, \mathrm{~S}=1\right)$ (Fig. S3) are $\pi$-like and delocalized on to the $\mathrm{CH}$ (both systems) and $\mathrm{CO}$ groups (only in the $\mathrm{d}^{2}$ system, as the $\mathrm{CO}$ group is on a nodal surface for $\left.\left[\mathrm{VO}(\mathrm{acac})_{2}\right]\right)$. Only very little direct spin delocalization can be expected in the $\mathrm{CH}_{3}$ group. Again, this is in good agreement with ligand-field theory, which for square-pyramidal and octahedral complexes predicts formation of SOMOs by mixing of the $d_{x y}, d_{x z}$, and $d_{y z}$ orbitals with ligand $\pi$-orbitals. The total spin-density plots (Fig. 3b) show regions of negative spin density, as the in-principle doubly occupied lower-energy MOs with amplitude on particularly $\mathrm{CH}_{3}$ groups are spin-polarized by the $\pi$-like SOMOs. This gives large positive ${ }^{13} \mathrm{C}$ NMR shifts for the $\mathrm{CO}$ groups and the relatively small paramagnetic shift changes for the $\mathrm{CH}_{3}$ groups, which is opposite to $\left[\mathrm{Ni}(\mathrm{acac})_{2}\left(\mathrm{H}_{2} \mathrm{O}\right)_{2}\right]$ and $\left[\mathrm{Cu}(\mathrm{acac})_{2}\right]$.

These qualitative arguments of spin-delocalization and spin-polarization contributions cancelling each other, based on spin density and SOMO plots, can be further investigated by a 
qualitative analysis of the HFC constants in terms of the direct SOMO contributions, corresponding to the spin-delocalization only, compared to the total values that result from both spin delocalization and spin polarization. This MO-based analysis is available in the ReSpect software, and the results are displayed in Table 2. In the $\mathrm{CH}_{3}$ group of the $\left[\mathrm{Cu}(\mathrm{acac})_{2}\right]\left(\mathrm{d}^{9}\right)$ complex, the positive $2.3 \mathrm{MHz}$ contribution of the single SOMO to the total coupling of $9.9 \mathrm{MHz}$, is reinforced by spin-polarization contribution of the same positive sign. This is in stark contrast to the saturation in the $\mathrm{d}^{1}$ complex [VO(acac)2], where the weak SOMO contribution of $0.2 \mathrm{MHz}$ is, in fact, counteracted by spin polarization, ending up in the negatively signed total of $-1.4 \mathrm{MHz}$ for the $\mathrm{CH}_{3}$ group. Precisely the opposite occurs in the CO group: in the $\mathrm{d}^{9}$ system the SOMO contribution of $0.2 \mathrm{MHz}$ is counteracted by the negative spin-polarization contribution resulting in a small and negative total coupling of $-0.3 \mathrm{MHz}$. Similarly, the $\mathrm{d}^{1}$ counterpart exhibits the opposite behavior in which the vanishing delocalization (SOMO) contribution is raised by spin polarization to the total of $5.9 \mathrm{MHz}$. Consequently, the reversed assignment of $\mathrm{CH}_{3}$ and $\mathrm{CO}$ signals in the two doublet systems is seen to result from the interplay of spin-delocalization and spin-polarization mechanisms. When there is a positive spin-delocalization contribution, as in $\mathrm{CH}_{3}$ in $\left[\mathrm{Cu}(\mathrm{acac})_{2}\right]$ and $\mathrm{CO}$ in $\left[\mathrm{VO}(\mathrm{acac})_{2}\right]$, a large positive shift results, whereas a small shift arises from a negative spin-polarization contribution.

While the triplet $\mathrm{d}^{2}$ system [V(acac)3] follows exactly the same pattern seen in the hyperfine couplings of $\mathrm{CH}_{3}$ and $\mathrm{CO}$ groups in [ $\left.\mathrm{VO}(\operatorname{acac})_{2}\right]$, the $\mathrm{d}^{8}$ system $\left[\mathrm{Ni}(\operatorname{acac})_{2}\left(\mathrm{H}_{2} \mathrm{O}\right)_{2}\right]$ does not behave similarly to the $\left[\mathrm{Cu}(\mathrm{acac})_{2}\right]$ case. Spin polarization is seen to counteract the delocalization contribution both for the $\mathrm{CH}_{3}$ and $\mathrm{CO}$ groups in the Ni complex. The very large contribution of one of the SOMOs $(10.5 \mathrm{MHz})$ at $\mathrm{CH}_{3}$ is sufficiently large not to be completely canceled by spin polarization, which results in the large positive total coupling of $3.3 \mathrm{MHz}$ and, consequently, to the large positive chemical shift. The small delocalization contribution to the CO hyperfine coupling is counteracted by spin polarization in the present $\mathrm{d}^{8}$ system. 
A localized $\mathrm{MO}$ analysis of the signs of the $\mathrm{CH}_{3}$ group signals in $\mathrm{Cr}(\mathrm{acac})_{3}$ (negative shift) and $\mathrm{Fe}(\mathrm{acac})_{3}$ (positive) and traced the change to the different balance in the two systems between spin-up and spin-down electrons in participating in the ligand-to-metal back-bonding was performed in Ref. ${ }^{46}$ This is due to the the fact the $S=5 / 2$ Fe(III) system lacks spin-up acceptor $3 \mathrm{~d}$ orbitals on the metal ion, leading to large spin density in the methyl groups, whereas the $S=3 / 2$ Cr(III) system allows a more balanced back-bonding to both spin-up and -down orbitals. Such reasoning is in line with our present observations.

In the present calculations, the assignment of the $\mathrm{CH}$ group of the acac-ligand is straightforward on account of the number of (near) equivalent nuclei being one half of the $\mathrm{CH}_{3}$ and CO groups, which undergo the above discussed reversal of the roles. In all the present systems both the spin-delocalization and spin-polarization effects on the ${ }^{13} \mathrm{CH}$ hyperfine coupling are of modest size, reflected in moderate ${ }^{13} \mathrm{C}$ contact shieldings that can be positive or negative.

For all the present systems there is a fair qualitative agreement of the computed isotropic and anisotropic chemical shift data with experiment. In particular, the diamagnetic $\left[\mathrm{Co}(\mathrm{acac})_{3}\right]$ system features accurately predicted shifts, hence the overall differences between calculated and experimental data arise due to the hyperfine contributions, instead of the orbital (chemical) shift part. Several factors contribute to the inability of the present computations to quantitatively reproduce the experimental hyperfine shifts and anisotropies, including the tendency of overestimating the spin delocalization by the approximate DFT functionals. ${ }^{46,77}$ However, the computations are clearly sufficiently accurate to aid in the assignment and analysis of the of the experimental signals, particularly concerning the reasons for the reversed assignment found in the present work.

\section{Conclusions}


Solid-state ${ }^{13} \mathrm{C}$ MAS NMR spectra of a series paramagnetic acetylacetonate complexes, [VO(acac $)_{2}$ ] $\left(d^{1}, S=1 / 2\right),\left[\mathrm{V}(\operatorname{acac})_{3}\right]\left(d^{2}, \mathrm{~S}=1\right),\left[\mathrm{Ni}(\operatorname{acac})_{2}\left(\mathrm{H}_{2} \mathrm{O}\right)_{2}\right]\left(d^{8}, \mathrm{~S}=1\right)$, and $\left[\mathrm{Cu}(\mathrm{acac})_{2}\right]\left(\mathrm{d}^{9}, \mathrm{~S}=1 / 2\right)$, were assigned by aid from quantum-chemical calculations of the full shielding tensor, performed using a modern version of the Kurland-McGarvey theory parameterized by relativistic first-principles electronic-structure calculations. A remarkable reversal in the assignment of $\delta_{\text {iso }}\left({ }^{13} \mathrm{C}\right)$ for $\mathrm{CH}_{3}$ and CO from the $\mathrm{d}^{1,2}$ to the $\mathrm{d}^{8,9}$ acac-complexes was revelated, which could be qualitatively explained from inspection of calculated spin-density and SOMO plots, as well as an analysis of the total contact hyperfine coupling constant to direct SOMO contributions versus the total coupling. This reversal of $\delta_{\text {iso }}\left({ }^{13} \mathrm{C}\right)$ is seen to be caused by the interplay between spin-delocalization and spin-polarization. Thus, SSNMR in combination with shielding calculations may provide an intuitive assignment for paramagnetic chemical shifts, which often may be difficult without computational aid.

Acknowledgements: Professor Christine McKenzie is gratefully acknowledged for providing the $\left[\mathrm{Cu}(\mathrm{acac})_{2}\right]$ sample. Drs Yusuke Nishiyama and Nghia Tuan Doung are thanked acquisition of ${ }^{13} \mathrm{C}$ MAS NMR spectra at ultra-fast MAS $(80 \mathrm{kHz})$. This work was funded by The Danish Council for Independent Research Science and Universe (grant DFF-7014-00198), the Academy of Finland (grant 296292) and University of Oulu (Kvantum Institute). Computational resources were provided by CSC-IT Center for Science (Espoo, Finland) and the Finnish Grid and Cloud Infrastructure project (persistent identifier urn:nbn:fi:research-infras-2016072533). CCDC 1983408 contains the supplementary crystallographic data for this paper. These data can be obtained free of charge from The Cambridge Crystallographic Data Centre via www.ccdc.cam.ac.uk/data_request/cif

\section{Electronic Supplementary Information:}


Python script used for finding $\mathrm{T}_{1}$ values, ssNake fitted ${ }^{13} \mathrm{C}$ MAS NMR spectra, physical contribution to the NMR shielding tensor (description and results to the calculated isotropic ${ }^{13} \mathrm{C}$ shielding constants), calculated SOMO plots, single-crystal XRD for [V(acac)3] (description, refined structure and selected geometric parameters), computationally optimized structure for each acac-complex, and calculated parameters of the g- and ZFS-tensors. 


\section{References:}

1. L. Lloyd, Handbook of Industrial Catalysts, Springer US, 1 edn., 2011.

2. M. Shao, R. Zhang, Z. Li, M. Wei, D. G. Evans and X. Duan, Chem. Commun., 2015, 51, 15880-15893.

3. W. Kaim, B. Schwederski and A. Klein, Bioinorganic Chemistry: Inorganic Elements in the Chemistry of Life: An Introduction and Guide, Wiley, 2nd edn., 2013.

4. A. J. Pell, G. Pintacuda and C. P. Grey, Prog. Nucl. Magn. Reson. Spectrosc., 2019, 111, 1271.

5. Y. Ishii, N. P. Wickramasinghe and S. Chimon, J. Am. Chem. Soc., 2003, 125, 3438-3439.

6. N. P. Wickramasinghe, M. Shaibat and Y. Ishii, J. Am. Chem. Soc., 2005, 127, 5796-5797.

7. G. Kervern, G. Pintacuda, Y. Zhang, E. Oldfield, C. Roukoss, E. Kuntz, E. Herdtweck, J.-M. Basset, S. Cadars, A. Lesage, C. Copéret and L. Emsley, J. Am. Chem. Soc., 2006, 128, $13545-$ 13552.

8. S. K. Kumara Swamy, A. Karczmarska, M. Makowska-Janusik, A. Kassiba and J. Dittmer, ChemPhysChem, 2013, 14, 1864-1870.

9. N. P. Wickramasinghe and Y. Ishii, J. Magn. Reson.J. Magn. Reson., 2006, 181, 233-243.

10. R. J. Kurland and B. R. McGarvey, J. Magn. Reson.J. Magn. Reson., 1970, 2, 286-301.

11. S. Moon and S. Patchkovskii, in Calculation of NMR and EPR Parameters: Theory and Applications, eds. M. Kaupp, M. Bühl and V. G. Malkin, Wiley-VCH Verlag GmbH \& Co. KGaA, Weinheim, FRG, 2004, pp. 325-338.

12. P. Hrobárik, R. Reviakine, A. V. Arbuznikov, O. L. Malkina, V. G. Malkin, F. H. Köhler and M. Kaupp, J. Chem. Phys., 2007, 126, 024107.

13. T. O. Pennanen and J. Vaara, Phys. Rev. Lett., 2008, 100, 133002.

14. A. Soncini and W. Van den Heuvel, J. Chem. Phys., 2013, 138, 021103.

15. B. Martin and J. Autschbach, J. Chem. Phys., 2015, 142, 054108.

16. J. Vaara, S. A. Rouf and J. Mareš, J. Chem. Theory Comput., 2015, 11, 4840-4849.

17. S. A. Rouf, J. Mareš and J. Vaara, J. Chem. Theory Comput., 2017, 13, 3731-3745.

18. D. Ganyushin and F. Neese, J. Chem. Phys., 2006, 125, 024103.

19. D. Ganyushin and F. Neese, J. Chem. Phys., 2013, 138, 104113.

20. E. Malkin, M. Repiský, S. Komorovský, P. Mach, O. L. Malkina and V. G. Malkin, J. Chem. Phys., 2011, 134, 044111.

21. S. A. Rouf, J. Mares and J. Vaara, J. Chem. Theory Comput., 2015, 11, 1683-1691.

22. S. A. Rouf, V. B. Jakobsen, J. Mareš, N. D. Jensen, C. J. McKenzie, J. Vaara and U. G. Nielsen, Solid State Nucl. Magn. Reson., 2017, 87, 29-37.

23. A. Mondal and M. Kaupp, J. Phys. Chem. Lett., 2018, 9, 1480-1484.

24. A. Mondal and M. Kaupp, J. Phys. Chem. C, 2019, 123, 8387-8405.

25. L. Benda, J. Mareš, E. Ravera, G. Parigi, C. Luchinat, M. Kaupp and J. Vaara, Angew. Chem. Int. Ed., 2016, 55, 14713-14717.

26. W. Van den Heuvel and A. Soncini, Phys. Rev. Lett., 2012, 109, 073001.

27. L. F. Chibotaru and L. Ungur, J. Chem. Phys., 2012, 137, 064112.

28. F. Gendron, K. Sharkas and J. Autschbach, J. Phys. Chem. Lett., 2015, 6, 2183-2188.

29. F. Gendron and J. Autschbach, J. Chem. Theory Comput., 2016, 12, 5309-5321.

30. M. Kaupp and F. H. Köhler, Coord. Chem. Rev., 2009, 253, 2376-2386.

31. J. Autschbach, in Annu. Rep. Comput. Chem., Elsevier, 2015, vol. 11, pp. 3-36.

32. Z. Ke, L. E. Jamieson, D. M. Dawson, S. E. Ashbrook and M. Bühl, Solid State Nucl. Magn. Reson., 2019, 101, 31-37.

33. H. Heise, F. H. Köhler and X. Xie, J. Magn. Reson., 2001, 150, 198-206. 
34. Z.-F. Xu, Y. Xie, W.-L. Feng and H. F. Schaefer, J. Phys. Chem. A, 2003, 107, 2716-2729.

35. F. Aquino, B. Pritchard and J. Autschbach, J. Chem. Theory Comput., 2012, 8, 598-609.

36. B. P. Pritchard, S. Simpson, E. Zurek and J. Autschbach, J. Chem. Educ., 2014, 91, 10581063.

37. J. Novotný, M. Sojka, S. Komorovsky, M. Nečas and R. Marek, J. Am. Chem. Soc., 2016, 138, 8432-8445.

38. P. L. Bora, J. Novotný, K. Ruud, S. Komorovsky and R. Marek, J. Chem. Theory Comput., 2019, 15, 201-214.

39. K. Levin and S. Kroeker, Solid State Nucl. Magn. Reson., 2019, 101, 101-109.

40. I. Bertini, C. Luchinat and G. Parigi, Solution NMR of Paramagnetic Molecules, Elsevier, 2001.

41. J. E. Harriman, Theoretical Foundations of Electron Spin Resonance, Academic Press, New York, 1978.

42. M. Kaupp, M. Bühl and V. G. Malkin, Calculation of NMR and EPR Parameters: Theory and Applications, eds. Wiley-VCH, Weinheim, 2004, p. 483.

43. L. Jeremias, J. Novotný, M. Repisky, S. Komorovsky and R. Marek, Inorg. Chem., 2018, 57, 8748-8759.

44. J. Novotný, D. Přichystal, M. Sojka, S. Komorovsky, M. Nečas and R. Marek, Inorg. Chem., 2018, 57, 641-652.

45. A. Lennartson, L. U. Christensen, C. J. McKenzie and U. G. Nielsen, Inorg. Chem., 2014, 53, 399-408.

46. B. Pritchard and J. Autschbach, Inorg. Chem., 2012, 51, 8340-8351.

47. E. Arslan, R. A. Lalancette and I. Bernal, Struct. Chem., 2017, 28, 201-212.

48. R. D. Peacock, J. Chem. Educ., 1971, 48, 133.

49. CrysAlisPro Software System, version 1.171.40.29a (2018); Rigaku Oxford Diffraction, Rigaku Corporation, Oxford, UK.

50. C. B. Hübschle, G. M. Sheldrick and B. Dittrich, J. Appl. Crystallogr., 2011, 44, 1281-1284.

51. O. V. Dolomanov, L. J. Bourhis, R. J. Gildea, J. A. Howard and H. Puschmann, J. Appl. Crystallogr., 2009, 42, 339-341.

52. G. M. Sheldrick, Acta Crystallogr. A, 2015, A71, 3-8.

53. G. M. Sheldrick, Acta Crystallogr. C, 2015, C71, 3-8.

54. R. P. Dodge, D. H. Templeton and A. Zalkin, J. Chem. Phys., 1961, 35, 55-67.

55. F. Sanz-Ruiz, S. Martínez-Carrera and S. García-Blanco, An. R. Soc. Esp. Fis. Quim., Ser. A, $1970,66,309$.

56. H. Golchoubian, Asian J. Chem., 2008, 20, 5834-5838.

57. R. K. Harris, E. D. Becker, S. M. C. d. Menezes, P. Granger, R. E. Hoffman and K. W. Zilm, $P A C, 2008, \mathbf{8 0}, 59$.

58. S. G. J. van Meerten, W. M. J. Franssen and A. P. M. Kentgens, J. Magn. Reson.J. Magn. Reson., 2019, 301, 56-66.

59. C. Adamo and V. Barone, J. Chem. Phys., 1999, 110, 6158-6170.

60. S. Grimme, J. Antony, S. Ehrlich and H. Krieg, J. Chem. Phys., 2010, 132, 154104.

61. S. Grimme, S. Ehrlich and L. Goerigk, J. Comput. Chem., 2011, 32, 1456-1465.

62. F. Weigend and R. Ahlrichs, Phys. Chem. Chem. Phys., 2005, 7, 3297-3305.

63. M. Dolg, U. Wedig, H. Stoll and H. Preuß, J. Chem. Phys., 1987, 86, 866-872.

64. TURBOMOLE, version 7.2 (2017); a development of University of Karlsruhe and Forschungszentrum Karlsruhe GmbH, 1989-2007, TURBOMOLE GmbH, since 2007. (available from http://www.turbomole.com)

65. F. Neese, Wiley Interdiscip. Rev. Comput. Mol. Sci., 2012, 2, 73-78. 
66. C. Angeli, R. Cimiraglia, S. Evangelisti, T. Leininger and J.-P. Malrieu, J. Chem. Phys., 2001, 114, 10252-10264.

67. C. Angeli, R. Cimiraglia and J.-P. Malrieu, Chem. Phys. Lett., 2001, 350, 297-305.

68. C. Angeli, R. Cimiraglia and J.-P. Malrieu, J. Chem. Phys., 2002, 117, 9138-9153.

69. B. Roos, Chem. Phys. Lett., 1972, 15, 153-159.

70. M. Douglas and N. M. Kroll, Ann. Phys. (N. Y.), 1974, 82, 89-155.

71. B. A. Hess, Phys. Rev. A, 1986, 33, 3742.

72. D. A. Pantazis, X.-Y. Chen, C. R. Landis and F. Neese, J. Chem. Theory Comput., 2008, 4, 908-919.

73. ReSpect, version 3.4.2 (2015); Relativistic Spectroscopy DFT program. M. Repisky, S. Komorovsky, V. G. Malkin, O. L. Malkina, M. Kaupp and K. Ruud, with contributions from R. Bast, U. Ekstrom, M. Kadek, S. Knecht, L. Konecny, E. Malkin and I. Malkin-Ondik. (www.respectprogram.org)

74. Gaussian 09, version E.01 Gaussian, Inc., Wallingford CT, 2016. M. J. Frisch, G. W. Trucks, H. B. Schlegel, G. E. Scuseria, M. A. Robb, J. R. Cheeseman, G. Scalmani, V. Barone, G. A. Petersson, H. Nakatsuji, X. Li, M. Caricato, A. Marenich, J. Bloino, B. G. Janesko, R. Gomperts, B. Mennucci, H. P. Hratchian, J. V. Ortiz, A. F. Izmaylov, J. L. Sonnenberg, D. Williams-Young, F. Ding, F. Lipparini, F. Egidi, J. Goings, B. Peng, A. Petrone, T. Henderson, D. Ranasinghe, V. G. Zakrzewski, J. Gao, N. Rega, G. Zheng, W. Liang, M. Hada, M. Ehara, K. Toyota, R. Fukuda, J. Hasegawa, M. Ishida, T. Nakajima, Y. Honda, O. Kitao, H. Nakai, T. Vreven, K. Throssell, J. A. Montgomery, Jr., J. E. Peralta, F. Ogliaro, M. Bearpark, J. J. Heyd, E. Brothers, K. N. Kudin, V. N. Staroverov, T. Keith, R. Kobayashi, J. Normand, K. Raghavachari, A. Rendell, J. C. Burant, S. S. Iyengar, J. Tomasi, M. Cossi, J. M. Millam, M. Klene, C. Adamo, R. Cammi, J. W. Ochterski, R. L. Martin, K. Morokuma, O. Farkas, J. B. Foresman and D. J. Fox,

75. K. Liu, D. Ryan, K. Nakanishi and A. McDermott, J. Am. Chem. Soc., 1995, 117, 6897-6906.

76. D. M. Doddrell and A. K. Gregson, Chem. Phys. Lett., 1974, 29, 512-515.

77. A. J. Cohen, P. Mori-Sánchez and W. Yang, Science, 2008, 321, 792-794. 


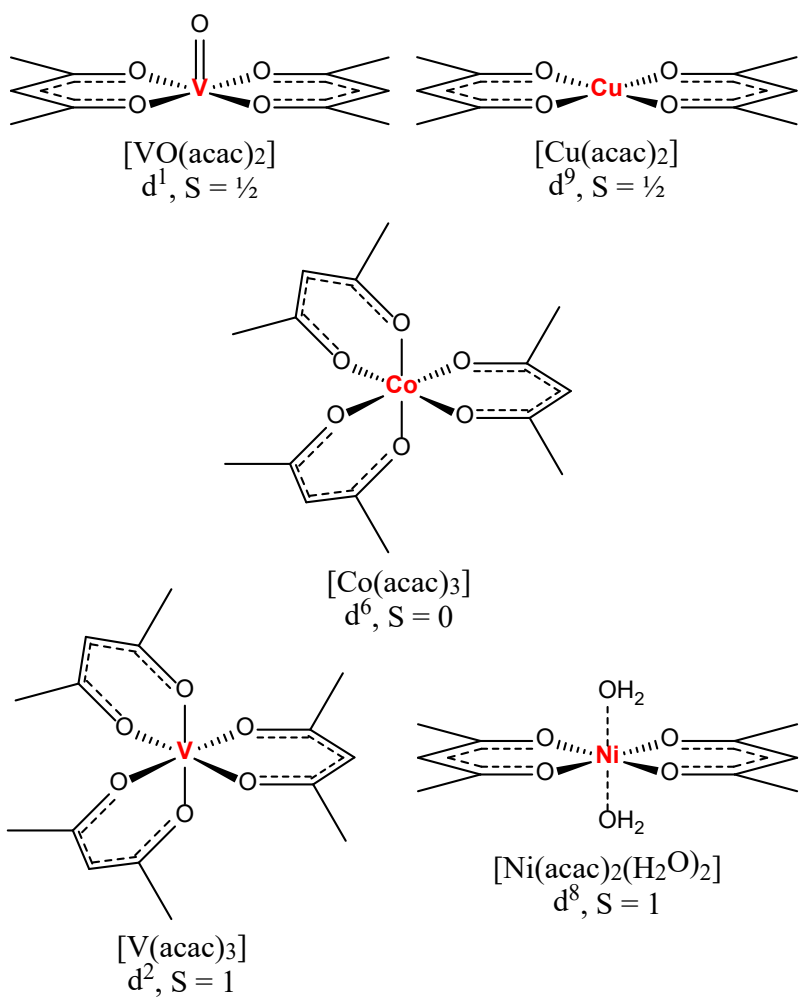

Fig. 1. The molecular structures of the metal acetylacetonate complexes investigated. 

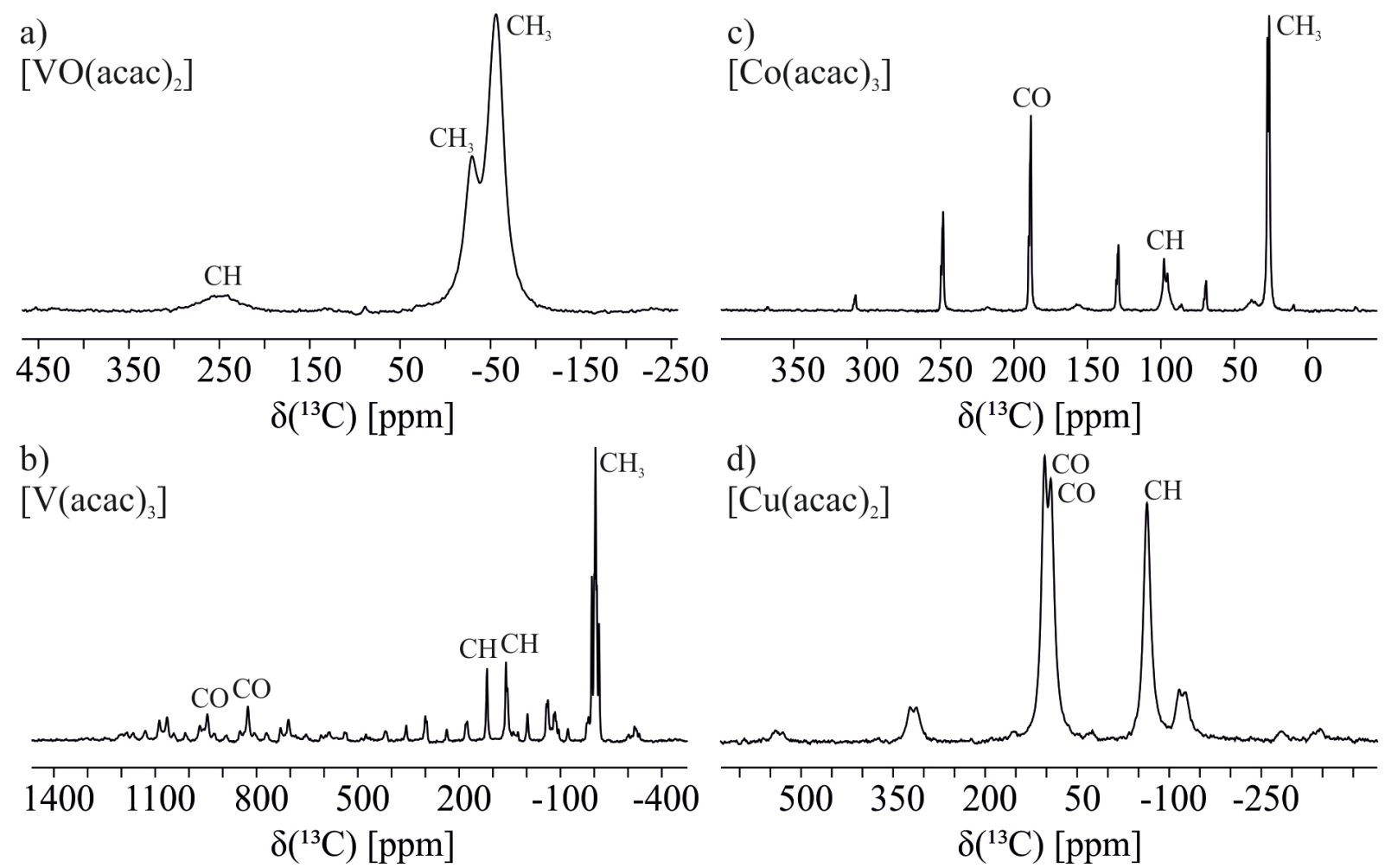

Fig. 2: ${ }^{13} \mathrm{C}$ MAS NMR spectra of a) $\left.\left[\mathrm{VO}(\mathrm{acac})_{2}\right], \mathrm{b}\right)\left[\mathrm{V}(\mathrm{acac})_{3}\right]$, c) diamagnetic $\left[\mathrm{Co}(\mathrm{acac})_{3}\right]$, and d) $\left[\mathrm{Cu}(\mathrm{acac})_{2}\right]$ with the isotropic resonances indicated. Simulations of the spectra are presented in Fig. S1. The reader is referred to previous studies ${ }^{22,45}$ for spectra of $\left[\mathrm{Ni}(\mathrm{acac})_{2}\left(\mathrm{H}_{2} \mathrm{O}\right)_{2}\right]$. 


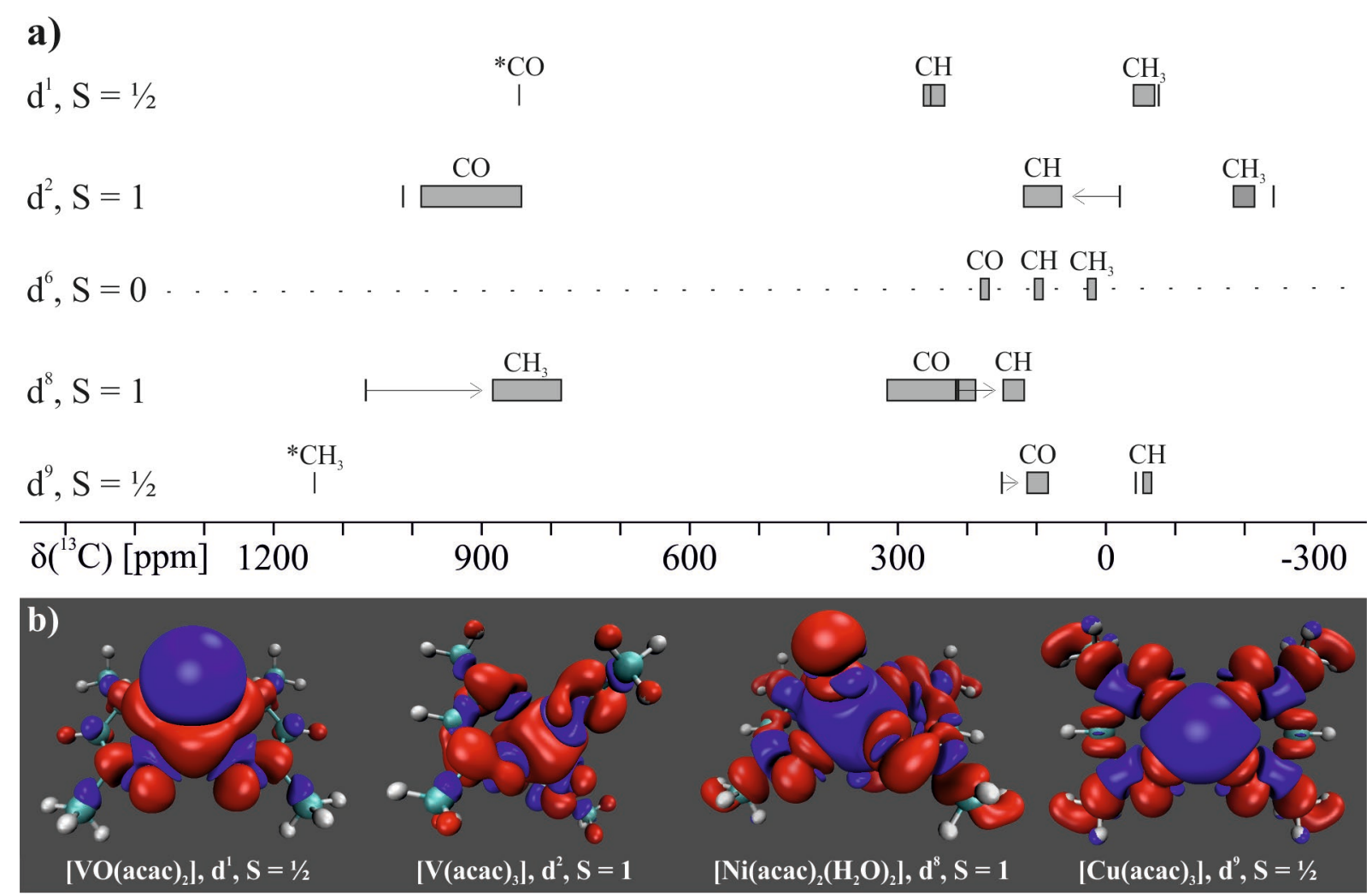

Fig. 3: a) Experimental chemical shift ranges (grey boxes) and calculated paramagnetic shifts (vertical lines) for each investigated spin system. *Experimental values are unavailable b) Plots of the calculated total spin densities for each system. These calculations were performed in ORCA using unrestricted DFT with the PBE0 functional at the scalar-relativistic DKH2 level, with uniform-quality def2-DZVP basis set. Regions of positive spin density are shown in red and regions of negative spin density in blue. 

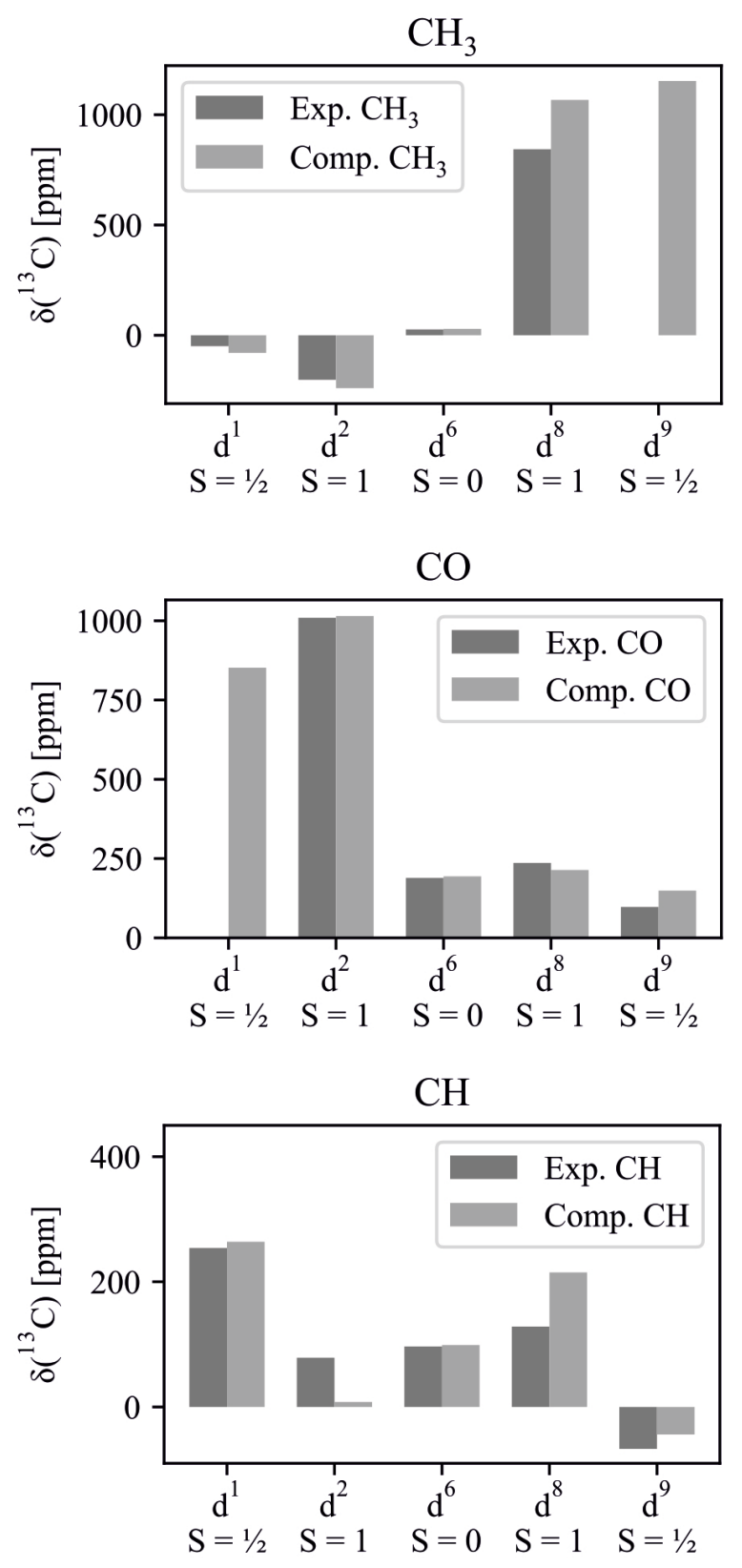

Fig. 4: The average of experimental $\delta\left({ }^{13} \mathrm{C}\right)$ and computational $\delta\left({ }^{13} \mathrm{C}\right)$ for each functional group of the acac ligands, shown as a dependence of d-electron configuration and the total spin quantum number $(S)$ for the investigated metal complexes. 

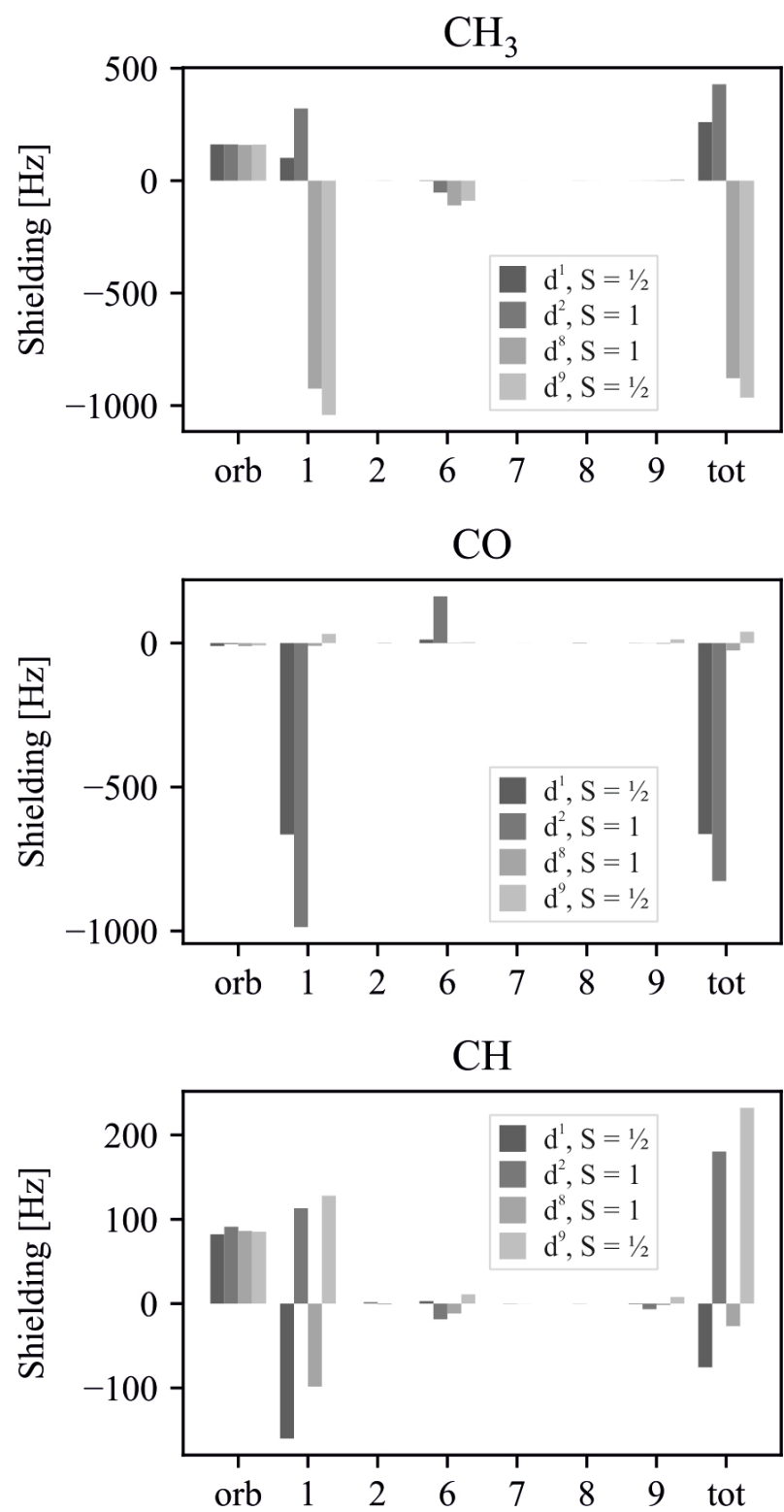

Fig. 5: Physical contributions to the total isotropic nuclear shielding constants from the different calculated terms (see Table S7 and Table S9 for the explanation of the various terms and corresponding numerical data, respectively). The contributions in each spin system are shown for each functional group. Due to the computational method used for the hyperfine coupling tensors, the terms 3 and 4 of Table S7 appear combined with terms 1 and 2, respectively. Term 5 does not contribute to the isotropic chemical shift. 
Table 1: ${ }^{13} \mathrm{C}$ NMR data for [VO(acac $\left.)_{2}\right],\left[\mathrm{V}(\mathrm{acac})_{3}\right],\left[\mathrm{Co}(\mathrm{acac})_{3}\right],\left[\mathrm{Ni}(\mathrm{acac})_{2}\left(\mathrm{H}_{2} \mathrm{O}\right)_{2}\right]$, and $\left[\mathrm{Cu}(\mathrm{acac})_{2}\right]$, with empirical simulation of total anisotropy $\left.\Delta=\delta_{z z}-\delta_{\text {iso }}, \eta=\left(\delta_{y y}-\delta_{x x}\right) / \Delta\right), T_{1}$, and computationally assisted assignment.

\begin{tabular}{|c|c|c|c|c|c|c|c|c|}
\hline \multirow[t]{2}{*}{ Compound } & \multirow{2}{*}{$\begin{array}{l}\text { Exp. } \\
\delta_{\text {iso }}\left({ }^{13} \mathrm{C}\right) \\
{[\mathrm{ppm}]}\end{array}$} & \multicolumn{2}{|c|}{ Exp. total anisotropy } & \multirow[t]{2}{*}{$\mathbf{T}_{1}[\mathrm{~ms}]$} & \multirow{2}{*}{$\begin{array}{l}\text { Comp. } \\
\delta_{\text {iso }}\left({ }^{13} \mathrm{C}\right) \\
{[\mathrm{ppm}]}\end{array}$} & \multicolumn{2}{|c|}{ Comp. total anisotropy } & \multirow[t]{2}{*}{ Assignment } \\
\hline & & $\Delta$ [ppm] & $\eta$ & & & $\Delta$ [ppm] & $\eta$ & \\
\hline \multirow{7}{*}{$\begin{array}{l}{\left[\mathrm{VO}(\mathrm{acac})_{2}\right]} \\
\mathrm{d}^{1}, \mathrm{~S}=1 / 2\end{array}$} & $\mathrm{n} / \mathrm{a}$ & $\mathrm{n} / \mathrm{a}$ & $\mathrm{n} / \mathrm{a}$ & $\mathrm{n} / \mathrm{a}$ & 852 & 323 & 0.5 & $\mathrm{R}-\mathrm{CO}$ \\
\hline & $266(10)^{\mathrm{a}}$ & $240(50)$ & $0.5(5)$ & $1.4(1)$ & 264 & 236 & 0.1 & R-CH-R \\
\hline & $242(10)^{\mathrm{a}}$ & $300(50)$ & $0.5(5)$ & $1.4(1)$ & & & & \\
\hline & $-29(4)^{a}$ & $70(30)$ & $1.0(2)$ & $1.9(2)$ & -72 & 31 & 0.8 & $\mathrm{R}-\mathrm{CH}_{3}$ \\
\hline & $-52(4)^{\mathrm{a}}$ & $70(30)$ & $1.0(2)$ & $2.7(1)$ & & & & \\
\hline & $-56(4)^{\mathrm{a}}$ & $70(30)$ & $0.9(2)$ & $2.7(1)$ & & & & \\
\hline & $-61(4)^{\mathrm{a}}$ & $70(30)$ & $0.7(2)$ & $2.7(1)$ & & & & \\
\hline \multirow{15}{*}{$\begin{array}{l}{\left[\mathrm{V}(\mathrm{acac})_{3}\right]} \\
\mathrm{d}^{2}, \mathrm{~S}=1\end{array}$} & $1090(4)^{\mathrm{a}}$ & $-355(28)$ & $0.9(1)$ & $6.8(5)$ & 1015 & -431 & 0.4 & $\mathrm{R}-\mathrm{CO}$ \\
\hline & $1056(4)$ & $-344(19)$ & $0.7(1)$ & $5.8(16)$ & & & & \\
\hline & 1021(4) & $-376(9)$ & $0.5(1)$ & $7.2(13)$ & & & & \\
\hline & $979(4)^{\mathrm{a}}$ & $-360(7)$ & $0.3(1)$ & $6.8(5)$ & & & & \\
\hline & $958(4)^{\mathrm{a}}$ & $-285(4)$ & $1.0(1)$ & $9.1(15)$ & & & & \\
\hline & $953(4)^{\mathrm{a}}$ & $-338(10)$ & $1.0(1)$ & $9.1(15)$ & & & & \\
\hline & $117(3)$ & $240(3)$ & $0.0(1)$ & $54.9(51)$ & 8 & 369 & 0.4 & R-CH-R \\
\hline & $62(2)$ & $243(13)$ & $0.3(2)$ & $39.5(67)$ & & & & \\
\hline & $57(2)$ & $437(69)$ & $0.4(2)$ & $35.9(37)$ & & & & \\
\hline & $-191(2)$ & $102(12)$ & $0.7(1)$ & $70.7(27)$ & -240 & 64 & 0.7 & $\mathrm{R}-\mathrm{CH}_{3}$ \\
\hline & $-198(2)$ & $154(6)$ & $0.8(1)$ & $73.2(24)$ & & & & \\
\hline & $-202(2)^{\mathrm{a}}$ & $96(6)$ & $1.0(1)$ & $62.5(8)$ & & & & \\
\hline & $-203(1)^{\mathrm{a}}$ & $90(6)$ & $1.0(1)$ & $62.5(8)$ & & & & \\
\hline & $-206(2)$ & $147(5)$ & $0.9(1)$ & $62.9(45)$ & & & & \\
\hline & $-212(2)$ & $145(6)$ & $0.8(2)$ & $61.8(2)$ & & & & \\
\hline \multirow{8}{*}{$\begin{array}{l}{\left[\mathrm{Co}(\text { acac })_{3}\right]} \\
d^{6}, S=0\end{array}$} & $190(1)$ & $-131(1)$ & $0.7(1)$ & $>52 \cdot 10^{5 \mathrm{c}}$ & 194 & -134 & 0.5 & $\mathrm{R}-\mathrm{CO}$ \\
\hline & $189(1)^{b}$ & $-131(2)$ & $0.6(1)$ & & & & & \\
\hline & $188(1)^{\mathrm{b}}$ & $-199(1)$ & $0.6(1)$ & & & & & \\
\hline & $98(1)$ & $93(22)$ & $0.0(1)$ & $>52 \cdot 10^{5 \mathrm{c}}$ & 99 & 108 & 0.2 & R-CH-R \\
\hline & $97(1)^{a}$ & $80(3)$ & $0.2(2)$ & & & & & \\
\hline & $95(1)$ & $89(1)$ & $0.2(2)$ & & & & & \\
\hline & $27(1)^{b}$ & $-27(2)$ & $0.0(1)$ & $>13 \cdot 10^{5 \mathrm{c}}$ & 29 & -29 & 0.1 & $\mathrm{R}-\mathrm{CH}_{3}$ \\
\hline & $26(1)^{b}$ & $-26(2)$ & $0.0(1)$ & & & & & \\
\hline \multirow{8}{*}{$\begin{array}{l}{\left[\mathrm{Ni}(\mathrm{acac})_{2}\left(\mathrm{H}_{2} \mathrm{O}\right)_{2}\right]^{\mathrm{d}}} \\
\mathrm{d}^{8}, \mathrm{~S}=1\end{array}$} & $891(20)$ & $\mathrm{n} / \mathrm{a}$ & $\mathrm{n} / \mathrm{a}$ & $0.1(1)$ & 1067 & 279 & 0.2 & $\mathrm{R}-\mathrm{CH}_{3}$ \\
\hline & $796(20)$ & & & 1.1(1) & & & & \\
\hline & $311(2)$ & $505(5)$ & $0.7(1)$ & $1.3(1)$ & 214 & 677 & 0.5 & R-CO \\
\hline & $245(1)$ & & & $1.1(1)$ & & & & \\
\hline & 201(1) & & & $1.4(1)$ & & & & \\
\hline & $188(1)$ & & & $1.1(1)$ & & & & \\
\hline & $134(1)$ & $243(7)$ & $0.0(1)$ & $2.9(1)$ & 215 & $-466^{\mathrm{e}}$ & $0.3^{\mathrm{e}}$ & R-CH-R \\
\hline & $123(1)$ & & & $3.2(1)$ & & & & \\
\hline \multirow{4}{*}{$\begin{array}{l}{\left[\mathrm{Cu}(\text { acac })_{2}\right]} \\
\mathrm{d}^{9}, \mathrm{~S}=1 / 2\end{array}$} & $\mathrm{n} / \mathrm{a}$ & $\mathrm{n} / \mathrm{a}$ & $\mathrm{n} / \mathrm{a}$ & $\mathrm{n} / \mathrm{a}$ & 1153 & 147 & 1.0 & $\mathrm{R}-\mathrm{CH}_{3}$ \\
\hline & 103(5) & $283(7)$ & $0.3(2)$ & $0.6(1)$ & 149 & 408 & 1.0 & $\mathrm{R}-\mathrm{CO}$ \\
\hline & $92(5)$ & 294(18) & $0.6(1)$ & $0.5(1)$ & & & & \\
\hline & $-65(7)$ & $-118(10)$ & $1.0(1)$ & $3.2(13)$ & -44 & -232 & 0.6 & R-CH-R \\
\hline
\end{tabular}

${ }^{\mathrm{a}} \delta_{\text {iso }}$ was found by deconvolution. ${ }^{58}$

${ }^{\mathrm{b}} \delta_{\text {iso }}$ consists of two or more overlapping resonances.

${ }^{\mathrm{c}}$ Estimated by $\tau_{\text {zero }}$ method, using: $T_{1}=\tau / \ln (2)$, where $\tau$ is selected at zero intensity.

${ }^{\mathrm{d}}$ Experimental data from previous work on $\left[\mathrm{Ni}(\operatorname{acac})_{2}\left(\mathrm{H}_{2} \mathrm{O}\right)_{2}\right] .{ }^{22}$

${ }^{\mathrm{e}}$ The sign change is due to the Haeberlen convention. Table S8 contains the calculated principal values of the shielding tensors. 
Table 2. Calculated contributions of the $\mathrm{SOMO}(\mathrm{s})$ to the total contact part of the hyperfine coupling constant (HFC) of the various ${ }^{13} \mathrm{C}$ nuclei in the studied systems. The effect of the spin-delocalization mechanism is seen from the contribution of the $\operatorname{SOMO}(\mathrm{s})$ and the spin-polarization mechanism corresponds to the difference of the total HFC and the SOMO contribution. The column "Case" indicates whether $(\mathrm{R})$ the spin polarization reinforces spin delocalization, $(\mathrm{C})$ the spin polarization counteracts spin delocalization, or (0) the SOMO contributions(s) are equal to zero and all of the contact HFC arises from spin polarization.

\begin{tabular}{|c|c|c|c|c|c|c|}
\hline Complex & $\begin{array}{l}\sigma(\text { tot }) \\
{[\mathrm{ppm}]}\end{array}$ & $\begin{array}{l}\sigma(c o n, \\
\text { term 1) } \\
\text { [ppm] }\end{array}$ & $\begin{array}{l}\text { HFC } \\
\text { (SOMO1) } \\
{[\mathrm{MHz}]} \\
\end{array}$ & $\begin{array}{l}\text { HFC } \\
\text { (SOMO2) } \\
{[\mathrm{MHz}]}\end{array}$ & $\begin{array}{l}\text { HFC } \\
\text { (tot) } \\
{[\mathrm{MHz}]} \\
\end{array}$ & Case \\
\hline \multicolumn{7}{|l|}{$\left[\mathrm{VO}(\mathrm{acac})_{2}\right]$} \\
\hline $\mathrm{CH}_{3}$ & 260.3 & 101.2 & 0.2 & -- & -1.4 & $\mathrm{C}$ \\
\hline $\mathrm{CO}$ & -663.3 & -664.8 & 0.0 & -- & 5.9 & 0 \\
\hline $\mathrm{CH}$ & -75.5 & -160.0 & 1.2 & -- & 1.4 & $\mathrm{R}$ \\
\hline \multicolumn{7}{|l|}{$\left[\mathrm{V}(\mathrm{acac})_{3}\right]$} \\
\hline $\mathrm{CH}_{3}$ & 428.5 & 321.0 & 0.2 & 0.1 & -1.1 & $\mathrm{C}$ \\
\hline $\mathrm{CO}$ & -826.8 & -986.5 & 0.9 & 0.8 & 3.5 & $\mathrm{R}$ \\
\hline $\mathrm{CH}$ & 180.4 & 113.1 & 1.9 & 1.2 & -0.4 & $\mathrm{C}$ \\
\hline \multicolumn{7}{|c|}{$\left[\mathrm{Ni}(\mathrm{acac})_{2}\left(\mathrm{H}_{2} \mathrm{O}\right)_{2}\right]$} \\
\hline $\mathrm{CH}_{3}$ & -878.3 & -924.5 & 10.5 & 0.0 & 3.3 & $\mathrm{C}$ \\
\hline $\mathrm{CO}$ & -26.6 & -9.7 & 0.9 & 0.0 & 0.1 & $\mathrm{C}$ \\
\hline $\mathrm{CH}$ & -25.7 & -98.4 & 0.0 & 0.0 & 0.4 & 0 \\
\hline \multicolumn{7}{|l|}{$\left[\mathrm{Cu}(\mathrm{acac})_{2}\right]$} \\
\hline $\mathrm{CH}_{3}$ & -964.7 & -1041.7 & 2.3 & -- & 9.9 & $\mathrm{R}$ \\
\hline $\mathrm{CO}$ & 39.6 & 32.2 & 0.2 & -- & -0.3 & $\mathrm{C}$ \\
\hline $\mathrm{CH}$ & 232.2 & 128.0 & 0.0 & -- & -1.2 & 0 \\
\hline
\end{tabular}


Electronic Supplementary Information:

\section{Remarkable reversal of ${ }^{13} C-N M R$ assignment in $d^{1}, d^{2}$ compared to $d^{8}$, $d^{9}$ acetylacetonate complexes: Analysis and explanation based on}

\section{Solid-state MAS NMR and computations}

Anders B. A. Andersen ${ }^{1}$, Ari Pyykkönen², Hans Jørgen Aa. Jensen¹, Vickie McKee ${ }^{1,3}$, Juha Vaara ${ }^{2}$, Ulla Gro Nielsen ${ }^{1}$

${ }^{1}$ Department of Physics, Chemistry and Pharmacy, University of Southern Denmark, Campusvej 55, 5230 Odense, Denmark

${ }^{2}$ NMR Research Unit, University of Oulu, FI-90014, Finland

${ }^{3}$ School of Chemical Sciences, Dublin City University, Glasnevin, Dublin 9, Ireland 


\section{Contents}

Page

S1. Python Script for Analyses of ${ }^{13} \mathrm{C}$ Inversion Recovery Data

Table S1. Computationally Optimized Structure of the VO(acac) ${ }_{2}$ Complex

Table S2. Computationally Optimized Structure of the [V(acac) $)_{2}$ Complex

Table S3. Computationally Optimized Structure of the [Co(acac) $\left.)_{3}\right]$ Complex

Table S4. Computationally Optimized Structure of the $\mathrm{Ni}(\operatorname{acac})_{2}\left(\mathrm{H}_{2} \mathrm{O}\right)_{2} \mathrm{Complex}$

Table S5. Computationally Optimized Structure of the $\left[\mathrm{Cu}(\mathrm{acac})_{2}\right]$ Complex

Table S6. Calculated Parameters of the $g$ - and Zero-Field Splitting Tensors

Table S7. Physical Contributions to the Nuclear Shielding Tensor

Table S9. Physical Contributions to the Calculated Isotropic ${ }^{13} \mathrm{C}$ Shielding Constants

S2. X-Ray Crystallography

Fig. S2. Perspective Diagram of [V(acac $\left.)_{3}\right]$

Table S10. Crystallographic Data and Structure Refinement for [V(acac $)_{3}$ ]

Table S11. Selected Geometric Parameters for [V(acac $\left.)_{3}\right]$ 


\section{S1. Python Script for Analyses of ${ }^{13} \mathrm{C}$ Inversion Recovery Data}

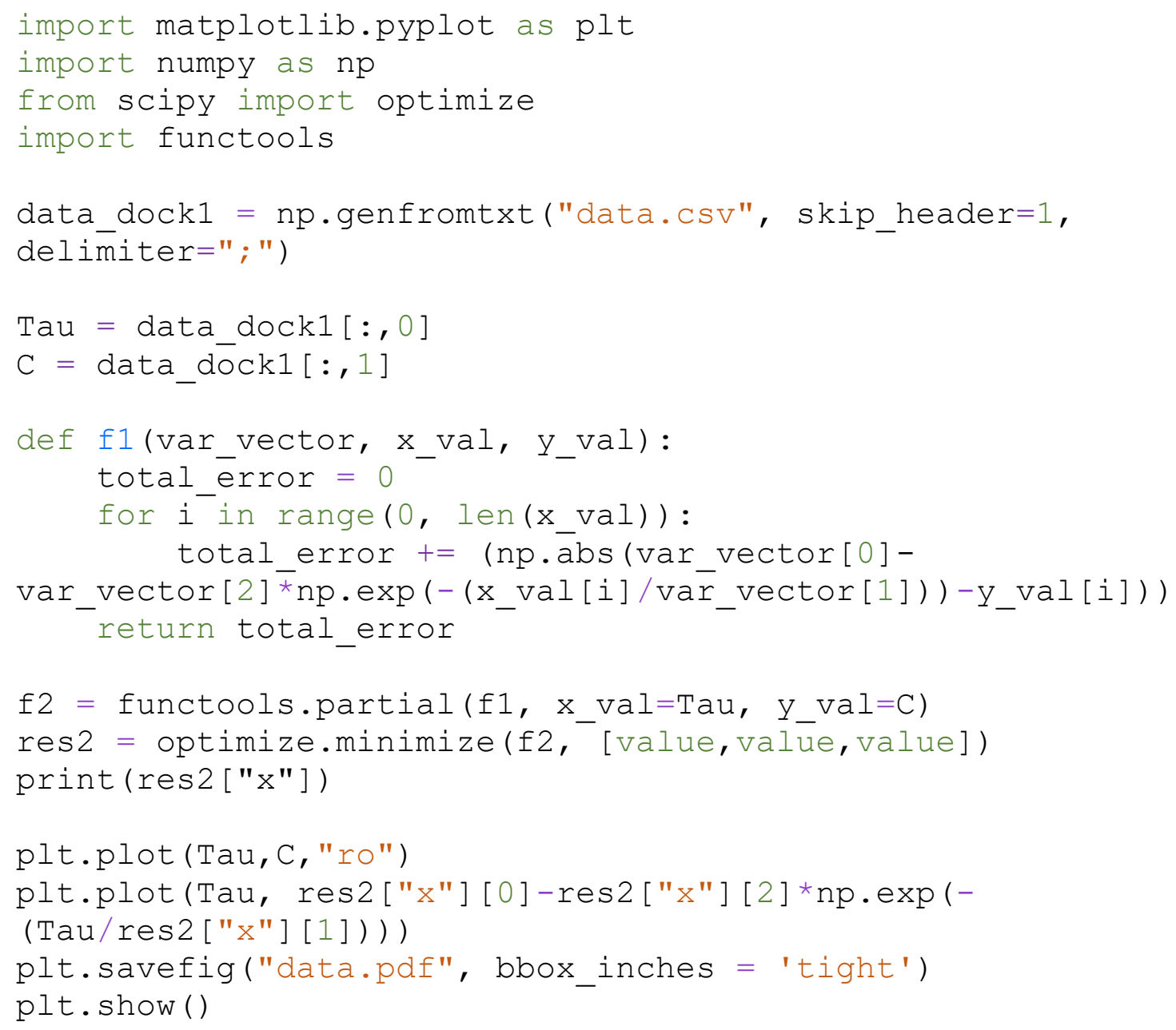


Table S1. Computationally optimized structure of the [VO(acac)2] complex (in $\AA$ ) in xyz-format. 30

$\begin{array}{rrrr}\mathrm{V} & -0.1137672 & 0.5100670 & 0.5476253 \\ \mathrm{C} & 3.6005943 & 1.7729958 & -1.0942710 \\ \mathrm{H} & 3.3694618 & 1.6514756 & -2.1546971 \\ \mathrm{H} & 4.6458363 & 1.5275432 & -0.9142893 \\ \mathrm{H} & 3.4240800 & 2.8225759 & -0.8463553 \\ \mathrm{C} & 2.6671657 & 0.9264424 & -0.2895176 \\ \mathrm{C} & 3.1719965 & -0.0185915 & 0.6023332 \\ \mathrm{H} & 4.2428843 & -0.1193809 & 0.7000945 \\ \mathrm{C} & 2.3493051 & -0.8930267 & 1.3111737 \\ \mathrm{C} & 2.9492930 & -1.9614249 & 2.1681553 \\ \mathrm{H} & 2.5929412 & -1.8343100 & 3.1930489 \\ \mathrm{H} & 4.0375806 & -1.9444676 & 2.1541900 \\ \mathrm{H} & 2.5925089 & -2.9349198 & 1.8241967 \\ \mathrm{O} & -0.3417353 & 1.5588155 & 1.6794681 \\ \mathrm{O} & 1.4329759 & 1.1281797 & -0.4999470 \\ \mathrm{O} & 1.0823886 & -0.8737891 & 1.2745286 \\ \mathrm{C} & -3.5317388 & -2.0146264 & 0.8369473 \\ \mathrm{H} & -3.6274665 & -1.8764987 & 1.9165022 \\ \mathrm{H} & -4.5202311 & -2.0269106 & 0.3811446 \\ \mathrm{H} & -3.0421231 & -2.9784685 & 0.6803123 \\ \mathrm{C} & -2.6614935 & -0.9306414 & 0.2859237 \\ \mathrm{C} & -3.1537224 & -0.0661923 & -0.6906389 \\ \mathrm{H} & -4.1737070 & -0.1876125 & -1.0245991 \\ \mathrm{C} & -2.3573099 & 0.8978622 & -1.3071652 \\ \mathrm{C} & -2.9143060 & 1.7380208 & -2.4114045 \\ \mathrm{H} & -2.2819028 & 1.6317225 & -3.2953886 \\ \mathrm{H} & -3.9409366 & 1.4736627 & -2.6584362 \\ \mathrm{H} & -2.8696127 & 2.7876641 & -2.1106314 \\ \mathrm{O} & -1.4839865 & -0.8882585 & 0.7541064 \\ \mathrm{O} & -1.1449728 & 1.1220919 & -1.0124097\end{array}$


Table S2. Computationally optimized structure of the [V(acac $\left.)_{2}\right]$ complex (in $\AA$ ) in xyz-format.

43

\begin{tabular}{|c|c|c|c|}
\hline V & 0.0000000 & 0.0000000 & -0.0671572 \\
\hline O & 0.8412623 & -1.1038732 & -1.4619491 \\
\hline O & -0.8412623 & 1.1038732 & -1.4619491 \\
\hline 0 & 0.7811689 & -1.0551215 & 1.4297208 \\
\hline O & 1.6145610 & 1.1236038 & -0.0095520 \\
\hline 0 & -0.7811689 & 1.0551215 & 1.4297208 \\
\hline O & -1.6145610 & -1.1236038 & -0.0095520 \\
\hline C & 0.7401444 & -0.9892349 & -2.7212026 \\
\hline $\mathrm{C}$ & -0.7401444 & 0.9892349 & -2.7212026 \\
\hline C & -0.0000000 & 0.0000000 & -3.3742963 \\
\hline $\mathrm{C}$ & 1.4982058 & -2.0024479 & -3.5238475 \\
\hline $\mathrm{C}$ & -1.4982058 & 2.0024479 & -3.5238475 \\
\hline $\mathrm{C}$ & 1.8990647 & -0.9545725 & 2.0207729 \\
\hline $\mathrm{C}$ & 2.6738780 & 1.0221855 & 0.6830724 \\
\hline C & 2.8566467 & 0.0280168 & 1.6745622 \\
\hline C & 2.1562011 & -1.8951396 & 3.1538901 \\
\hline $\mathrm{C}$ & 3.7640883 & 1.9988540 & 0.3871226 \\
\hline $\mathrm{C}$ & -2.6738780 & -1.0221855 & 0.6830724 \\
\hline C & -1.8990647 & 0.9545725 & 2.0207729 \\
\hline C & -2.8566467 & -0.0280168 & 1.6745622 \\
\hline C & -3.7640883 & -1.9988540 & 0.3871226 \\
\hline C & -2.1562011 & 1.8951396 & 3.1538901 \\
\hline $\mathrm{H}$ & 1.1512488 & -3.0039666 & -3.2581511 \\
\hline $\mathrm{H}$ & 2.5574843 & -1.9500585 & -3.2599290 \\
\hline $\mathrm{H}$ & 1.3851614 & -1.8533662 & -4.5967987 \\
\hline $\mathrm{H}$ & -2.5574843 & 1.9500585 & -3.2599290 \\
\hline $\mathrm{H}$ & -1.1512488 & 3.0039666 & -3.2581511 \\
\hline $\mathrm{H}$ & -1.3851614 & 1.8533662 & -4.5967 \\
\hline $\mathrm{H}$ & 2.0468270 & -2.9276199 & 2.8111074 \\
\hline $\mathrm{H}$ & 1.4108675 & -1.7384867 & 3.9401959 \\
\hline $\mathrm{H}$ & 3.1503798 & -1.7646693 & 3.5809 \\
\hline $\mathrm{H}$ & 4.0504035 & 1.9212525 & -0.6661954 \\
\hline $\mathrm{H}$ & 3.3972277 & 3.0179184 & 0.5412535 \\
\hline $\mathrm{H}$ & 4.6437588 & 1.8387312 & 1.0096077 \\
\hline $\mathrm{H}$ & -3.3972277 & -3.0179184 & 0.5412535 \\
\hline $\mathrm{H}$ & -4.0504035 & -1.9212525 & -0.6661954 \\
\hline $\mathrm{H}$ & -4.6437588 & -1.8387312 & 1.0096077 \\
\hline $\mathrm{H}$ & -1.4108675 & 1.7384867 & 3.9401959 \\
\hline $\mathrm{H}$ & -2.0468270 & 2.9276199 & 2.8111074 \\
\hline $\mathrm{H}$ & -3.1503798 & 1.7646693 & 3.5809698 \\
\hline $\mathrm{H}$ & -0.0000000 & 0.0000000 & -4.4553527 \\
\hline $\mathrm{H}$ & 3.7950007 & 0.0290035 & 2.2137531 \\
\hline $\mathrm{H}$ & -3.7950007 & -0.0290035 & 2.213753 \\
\hline
\end{tabular}


Table S3. Computationally optimized structure of the $\left[\mathrm{Co}(\mathrm{acac})_{3}\right]$ complex (in $\AA$ ) in xyz-format.

43

$\begin{array}{lrrr}\mathrm{Co} & 0.0000000 & -0.0000000 & -0.0214882 \\ \mathrm{O} & 0.8178309 & -1.1354470 & -1.2730913 \\ \mathrm{O} & -0.8178309 & 1.1354470 & -1.2730913 \\ \mathrm{O} & 0.6592664 & -1.1337350 & 1.3233206 \\ \mathrm{O} & 1.5076153 & 1.1136343 & -0.1126396 \\ \mathrm{O} & -0.6592664 & 1.1337350 & 1.3233206 \\ \mathrm{O} & -1.5076153 & -1.1136343 & -0.1126396 \\ \mathrm{C} & 0.7213200 & -0.9962773 & -2.5226061 \\ \mathrm{C} & -0.7213200 & 0.9962773 & -2.5226061 \\ \mathrm{C} & 0.0000000 & 0.0000000 & -3.1807830 \\ \mathrm{C} & 1.4686884 & -2.0197008 & -3.3242566 \\ \mathrm{C} & -1.4686884 & 2.0197008 & -3.3242566 \\ \mathrm{C} & 1.7799739 & -0.9871532 & 1.8828603 \\ \mathrm{C} & 2.5228459 & 0.9923553 & 0.6250527 \\ \mathrm{C} & 2.7120396 & 0.0111209 & 1.5982907 \\ \mathrm{C} & 2.0887327 & -2.0058628 & 2.9391599 \\ \mathrm{C} & 3.5891396 & 2.0208215 & 0.3937673 \\ \mathrm{C} & -2.5228459 & -0.9923553 & 0.6250527 \\ \mathrm{C} & -1.7799739 & 0.9871532 & 1.8828603 \\ \mathrm{C} & -2.7120396 & -0.0111209 & 1.5982907 \\ \mathrm{C} & -3.5891396 & -2.0208215 & 0.3937673 \\ \mathrm{C} & -2.0887327 & 2.0058628 & 2.9391599 \\ \mathrm{H} & 1.1037598 & -3.0147041 & -3.0609096 \\ \mathrm{H} & 2.5263565 & -1.9809022 & -3.0545926 \\ \mathrm{H} & 1.3607897 & -1.8633212 & -4.3962783 \\ \mathrm{H} & -2.5263565 & 1.9809022 & -3.0545926 \\ \mathrm{H} & -1.1037598 & 3.0147041 & -3.0609096 \\ \mathrm{H} & -1.3607897 & 1.8633212 & -4.3962783 \\ \mathrm{H} & 2.0836500 & -2.9997130 & 2.4862748 \\ \mathrm{H} & 1.2995682 & -1.9895937 & 3.6939846 \\ \mathrm{H} & 3.0519875 & -1.8282328 & 3.4146675 \\ \mathrm{H} & -3.6349049 & -0.0218059 & 2.1591761 \\ \mathrm{H} & 3.8904555 & 1.9951687 & -0.6554824 \\ \mathrm{H} & 3.1726697 & 3.0120378 & 0.5867792 \\ \mathrm{H} & 4.4598021 & 1.8630264 & 1.0280643 \\ \mathrm{H} & -3.1726697 & -3.0120378 & 0.5867792 \\ \mathrm{H} & -3.8904555 & -1.9951687 & -0.6554824 \\ \mathrm{H} & -4.4598021 & -1.8630264 & 1.0280643 \\ \mathrm{H} & -1.2995682 & 1.9895937 & 3.6939846 \\ \mathrm{H} & -2.0836500 & 2.9997130 & 2.4862748 \\ \mathrm{H} & 0.0000000 & -0.0000000 & -4.2608121 \\ \mathrm{H} & 3.6349049 & 0.0218059 & 2.1591761 \\ \mathrm{H} & -1.8282328 & 3.4146675 \\ \mathrm{H} & -1.05875 & & \end{array}$


Table S4. Computationally optimized structure of the $\left[\mathrm{Ni}(\mathrm{acac})_{2}\left(\mathrm{H}_{2} \mathrm{O}\right)_{2}\right]$ complex (in $\AA$ ) in xyzformat.

35

\begin{tabular}{|c|c|c|c|}
\hline $\mathrm{C}$ & 3.6415013 & 1.8271403 & -1.0614808 \\
\hline $\mathrm{H}$ & 3.3026695 & 1.9277626 & -2.0946475 \\
\hline $\mathrm{H}$ & 4.6427571 & 1.3990589 & -1.0407361 \\
\hline $\mathrm{H}$ & 3.6727414 & 2.8333009 & -0.6360680 \\
\hline $\mathrm{C}$ & 2.6413748 & 1.0085924 & -0.2949123 \\
\hline $\mathrm{C}$ & 3.0965610 & -0.1224177 & 0.4140297 \\
\hline $\mathrm{H}$ & 4.1501517 & -0.3585592 & 0.3560255 \\
\hline $\mathrm{C}$ & 2.3243775 & -0.8123081 & 1.362642 \\
\hline $\mathrm{C}$ & 3.0015444 & -1.8084644 & 2.2617813 \\
\hline $\mathrm{H}$ & 2.9121825 & -1.4678241 & 3.2964058 \\
\hline $\mathrm{H}$ & 4.0549519 & -1.9450566 & 2.02149 \\
\hline $\mathrm{H}$ & 2.4799494 & -2.7659595 & 2.19743 \\
\hline O & -0.6116690 & 1.5760132 & 1.70 \\
\hline O & 1.4539765 & 1.4143526 & -0.32401 \\
\hline 0 & 1.0868188 & -0.6562233 & 1.5389 \\
\hline $\mathrm{Ni}$ & -0.1089682 & 0.2109667 & 0.12 \\
\hline $\mathrm{C}$ & -3.6436472 & -2.1133052 & 0.6263 \\
\hline $\mathrm{H}$ & -3.6571040 & -2.0864988 & 1.7183. \\
\hline $\mathrm{H}$ & -4.6588480 & -2.00461 & 0.24 \\
\hline $\mathrm{H}$ & -3.2530789 & -3.0915183 & 0.33498 \\
\hline C & -2.7187117 & -1.0415280 & 0.1215 \\
\hline C & -3.2239569 & -0.0750656 & -0.7 \\
\hline $\mathrm{H}$ & -4.2710363 & -0.1397935 & -1.01115 \\
\hline $\mathrm{C}$ & -2.4778301 & 0.9645716 & -1.32836 \\
\hline $\mathrm{C}$ & -3.1734017 & 1.9112733 & -2.2664 \\
\hline $\mathrm{H}$ & -2.6544648 & 1.9044219 & -3.22749 \\
\hline $\mathrm{H}$ & -4.2225996 & 1.6610758 & -2.41659 \\
\hline $\mathrm{H}$ & -3.0965891 & 2.9255763 & -1.86736 \\
\hline O & 0.5970692 & -1.2640134 & -1.2758543 \\
\hline O & -1.5267511 & -1.1157767 & 0.53852 \\
\hline O & -1.2561271 & 1.1895926 & -1.1401087 \\
\hline $\mathrm{H}$ & 0.1458532 & -2.0206371 & -0.8825963 \\
\hline $\mathrm{H}$ & -0.0806037 & 1.1508626 & 2.3883916 \\
\hline $\mathrm{H}$ & 1.5348625 & -1.3601519 & -1.0581007 \\
\hline $\mathrm{H}$ & -0.1039553 & 2.3451512 & 1.4199550 \\
\hline
\end{tabular}


Table S5. Computationally optimized structure of the $\left[\mathrm{Cu}(\mathrm{acac})_{2}\right]$ complex (in $\AA$ ) in xyz-format.

$\begin{array}{lrrr}29 & & & \\ \mathrm{Cu} & 0.0000135 & -0.0000767 & -0.0000627 \\ \mathrm{C} & 3.6261475 & 1.8920932 & -0.9527389 \\ \mathrm{H} & 3.5595942 & 1.7648501 & -2.0354718 \\ \mathrm{H} & 4.6564886 & 1.7496289 & -0.6307351 \\ \mathrm{H} & 3.3126940 & 2.9146145 & -0.7301813 \\ \mathrm{C} & 2.6806087 & 0.9364528 & -0.2885076 \\ \mathrm{C} & 3.1724091 & 0.0194028 & 0.6421157 \\ \mathrm{H} & 4.2316322 & 0.0247609 & 0.8549722 \\ \mathrm{C} & 2.3675707 & -0.9026612 & 1.3137174 \\ \mathrm{C} & 2.9902190 & -1.8458429 & 2.2991229 \\ \mathrm{H} & 2.5232453 & -1.6996086 & 3.2757894 \\ \mathrm{H} & 4.0665391 & -1.7066232 & 2.3853566 \\ \mathrm{H} & 2.7771609 & -2.8724212 & 1.9928890 \\ \mathrm{O} & 1.4711993 & 1.0467933 & -0.6395592 \\ \mathrm{O} & 1.1178552 & -1.0256479 & 1.1693401 \\ \mathrm{C} & -3.6258086 & -1.8936495 & 0.9510087 \\ \mathrm{H} & -3.5597087 & -1.7672134 & 2.0338620 \\ \mathrm{H} & -4.6560990 & -1.7514315 & 0.6287347 \\ \mathrm{H} & -3.3117910 & -2.9158487 & 0.7277742 \\ \mathrm{C} & -2.6804723 & -0.9370865 & 0.2878163 \\ \mathrm{C} & -3.1723641 & -0.0196224 & -0.6423529 \\ \mathrm{H} & -4.2315552 & -0.0251133 & -0.8553643 \\ \mathrm{C} & -2.3676489 & 0.9029976 & -1.3133339 \\ \mathrm{C} & -2.9905973 & 1.8475962 & -2.2971906 \\ \mathrm{H} & -2.5239981 & 1.7027990 & -3.2742478 \\ \mathrm{H} & -4.0669597 & 1.7085727 & -2.3832187 \\ \mathrm{H} & -2.7773678 & 2.8737081 & -1.9895003 \\ \mathrm{O} & -1.4710965 & -1.0473175 & 0.6390024 \\ \mathrm{O} & -1.1179101 & 1.0258946 & -1.1690365\end{array}$

Table S6. Calculated parameters of the $g$ - and zero-field splitting (ZFS) tensors.

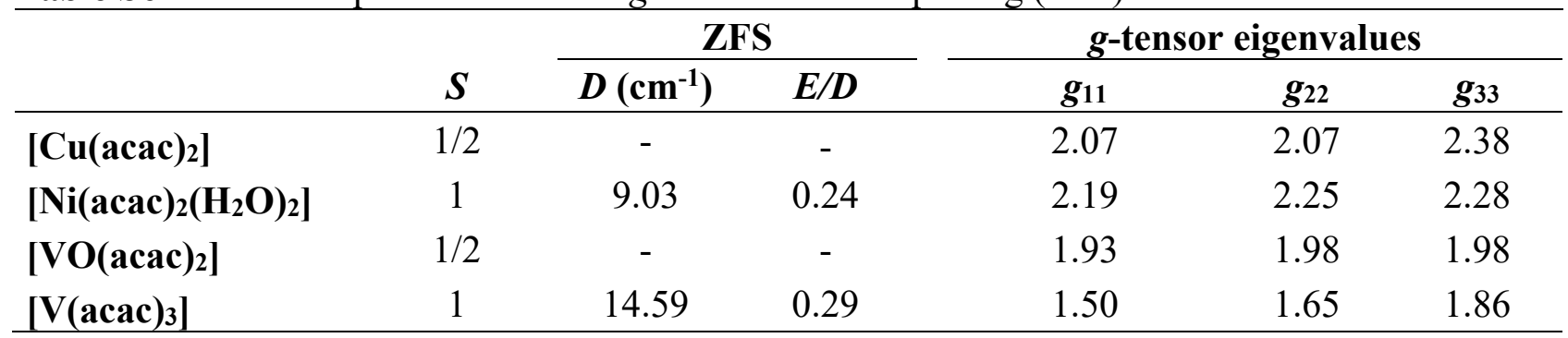


Table S7. The different physical contributions to the calculated nuclear shielding tensor according to the break-down by Pennanen and Vaara. ${ }^{1,2}$ The present calculations employ fully relativistic HFC tensors. The terms 3 and 4 are therefore included in terms 1 and 2, respectively, and are identified from the rank-0 (isotropic) and rank-2 (anisotropic, but symmetric) parts of the calculated, relativistic HFC tensors.

\begin{tabular}{|c|c|c|c|c|}
\hline Term & Contribution to $\sigma_{\varepsilon \tau}^{\alpha}$ & Origin & $\begin{array}{l}\text { (SS)NMR } \\
\text { Observable }\end{array}$ & $\begin{array}{l}\text { Tensorial } \\
\text { Rank }\end{array}$ \\
\hline orb & $\sigma_{\text {orb }}$ & orbital interactions & chemical shift tensor & $0,1,2$ \\
\hline $1^{\text {st }}$ & $g_{e} A_{\mathrm{con}}<S_{\varepsilon} S_{\tau}>$ & $\begin{array}{l}\text { nonrelativistic } \\
\text { contact HFC }\end{array}$ & term in contact shift & 0,2 \\
\hline $2^{\text {nd }}$ & $g_{e} \Sigma_{\mathrm{b}} A b \tau^{\operatorname{dip}}<S_{\varepsilon} S_{\tau}>$ & $\begin{array}{l}\text { nonrelativistic } \\
\text { dipolar HFC }\end{array}$ & term in dipolar shift & $0,1,2$ \\
\hline $3^{\text {rd }}$ & $g_{e} A \mathrm{PC}<S_{\varepsilon} S_{\tau}>$ & $\begin{array}{l}\text { isotropic rel. } \\
\text { correction to HFC }\end{array}$ & term in contact shift & 0,2 \\
\hline $4^{\text {th }}$ & $g_{e} \Sigma_{b} A_{b \tau}{ }^{\mathrm{dip}, 2}<S_{\varepsilon} S_{b}>$ & $\begin{array}{l}\text { rank-2 rel. } \\
\text { correction to HFC }\end{array}$ & term in dipolar shift & $0,1,2$ \\
\hline $5^{\text {th }}$ & $g_{e} \Sigma_{b} A_{b \tau}{ }^{\text {as }}<S_{\varepsilon} S_{b}>$ & $\begin{array}{l}\text { rank-1 rel. } \\
\text { correction to HFC }\end{array}$ & $\begin{array}{l}\text { correction to tensor } \\
\text { anisotropy }\end{array}$ & 1,2 \\
\hline $6^{\text {th }}$ & $\Delta g_{\text {iso }} A_{\text {con }}<S_{\varepsilon} S_{\tau}>$ & $\begin{array}{l}\text { isotropic part of } g- \\
\text { shift }\end{array}$ & term in contact shift & 0,2 \\
\hline $7^{\text {th }}$ & $\Delta g_{\text {iso }} \Sigma_{b} A b \tau^{\text {dip }}<S_{\varepsilon} S_{b}>$ & $\begin{array}{l}\text { isotropic part of } g- \\
\text { shift }\end{array}$ & term in dipolar shift & $0,1,2$ \\
\hline $8^{\text {th }}$ & $A_{\mathrm{con}} \Sigma_{a} \Delta \tilde{g}_{e a}<S_{a} S_{\tau}>$ & $\begin{array}{l}\text { anisotropic part of } \\
g \text {-shift }\end{array}$ & $\begin{array}{l}\text { anisotropic contact } \\
\text { shift }\end{array}$ & $0,1,2$ \\
\hline $9^{\text {th }}$ & $\sum_{a b} \Delta \tilde{g}_{e a} A b \tau^{\mathrm{dip}}<S_{a} S_{b}>$ & $\begin{array}{l}\text { anisotropic part of } \\
g \text {-shift }\end{array}$ & pseudocontact shift & $0,1,2$ \\
\hline Total & $\boldsymbol{\sigma}_{\mathrm{orb}}-\frac{\mu_{\mathrm{B}}}{\gamma \hbar k T} \boldsymbol{g} \cdot\langle\boldsymbol{S} \boldsymbol{S}\rangle \cdot \boldsymbol{A}$ & $\begin{array}{l}\text { total shielding } \\
\text { tensor }\end{array}$ & total shift & $0,1,2$ \\
\hline
\end{tabular}

${ }^{a} g_{e}=$ the free-electron $g$-factor, $A_{\mathrm{con}}=$ nonrelativistic contact part of HFC constant, $A_{\mathrm{PC}}=$ its

relativistic correction, $A_{a b}{ }^{\mathrm{dip}}=$ nonrelativistic dipolar part of the HFC tensor, $A_{a b}{ }^{\mathrm{dip}, 2}=$ its relativistic correction, $A a b^{\text {as }}=$ antisymmeric part of the (relativistic) HFC tensor, $\Delta g_{\text {iso }}=$ isotropic part of the $g$ shift tensor and $\Delta \tilde{g}_{a b}=$ anisotropic part of the $g$-shift tensor. 

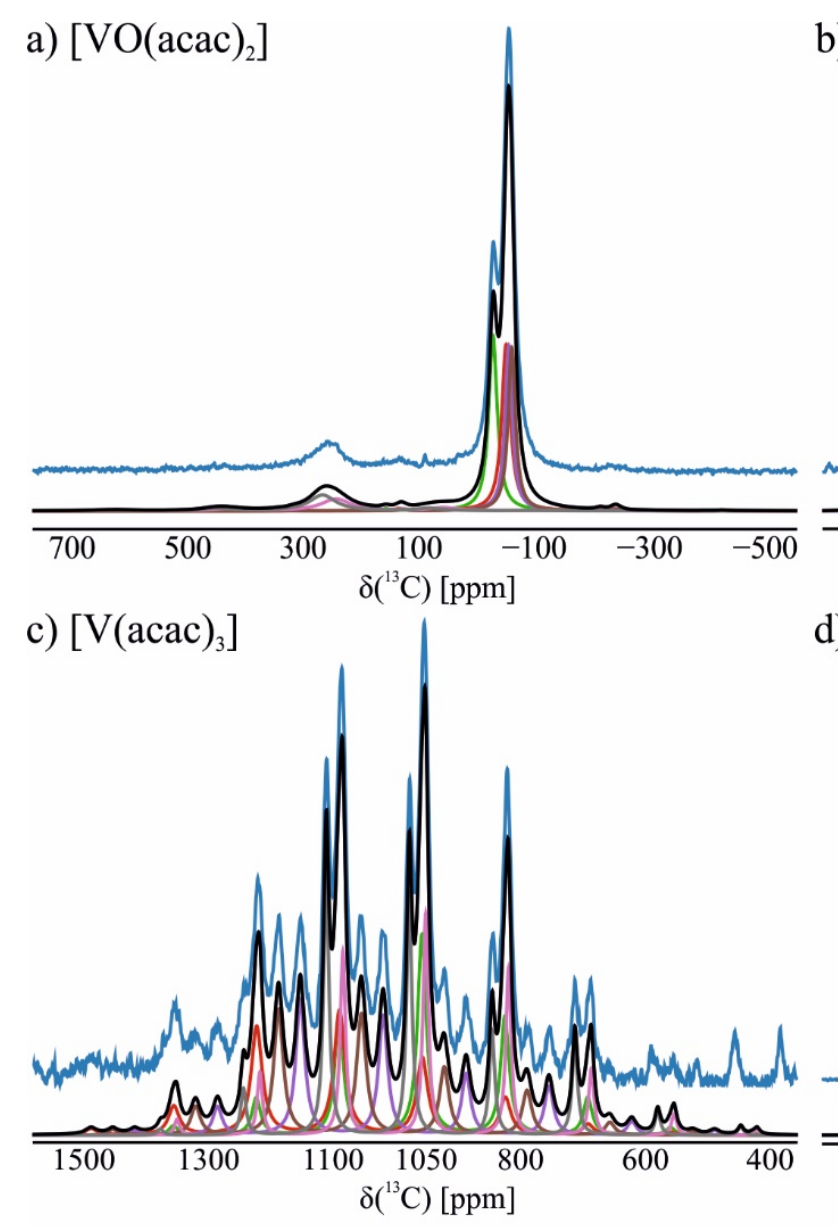

e) $\left[\mathrm{Co}(\mathrm{acac})_{3}\right]$

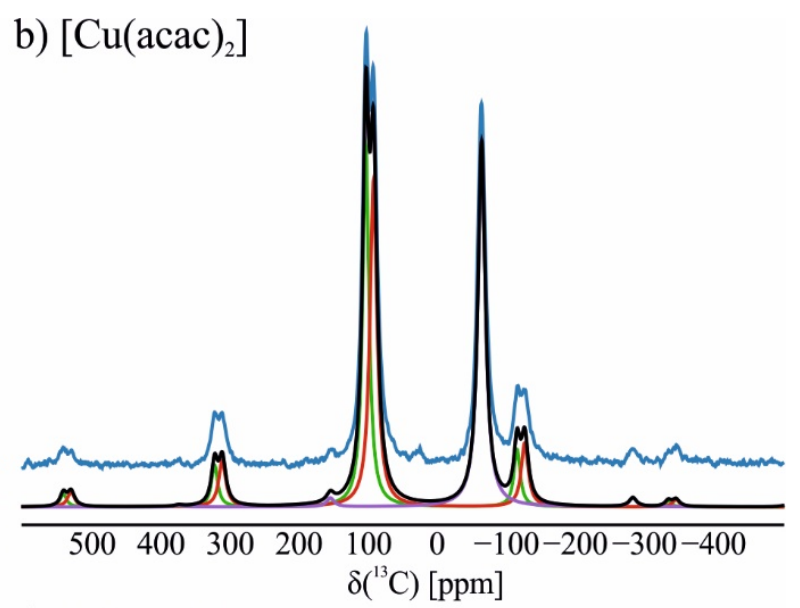

d) $\left[\mathrm{V}(\mathrm{acac})_{3}\right]$

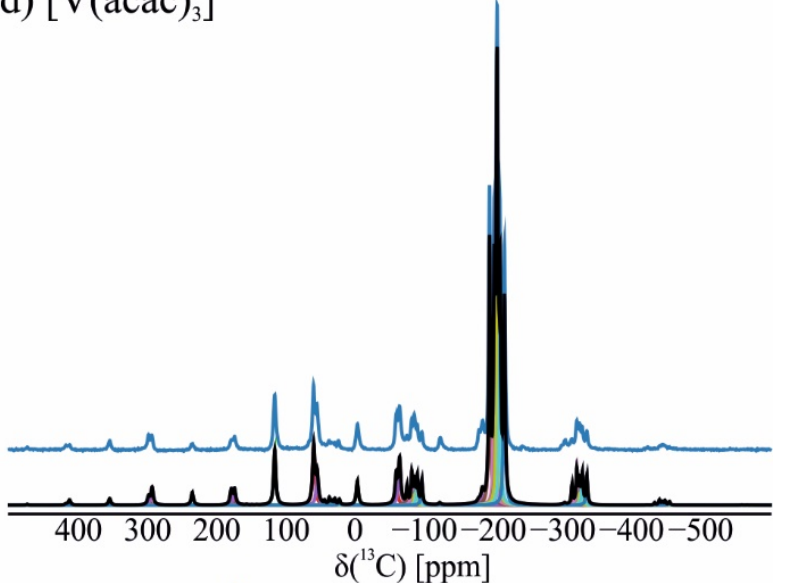
$\delta\left({ }^{13} \mathrm{C}\right)[\mathrm{ppm}]$

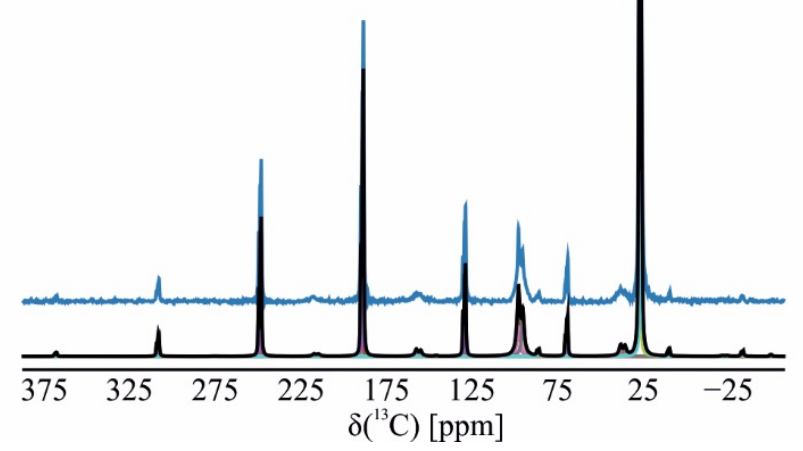

Fig. S1. Simulations (black line) of the experimental (blue line) ${ }^{13} \mathrm{C}$ MAS NMR spectra of a) $\left[\mathrm{VO}(\mathrm{acac})_{2}\right]$ at $28 \mathrm{kHz}$ spinning speed, b) $\left[\mathrm{Cu}(\mathrm{acac})_{2}\right]$ at $33 \mathrm{kHz}$ spinning speed, c) carbonyl region of $\left[\mathrm{V}(\mathrm{acac})_{3}\right]$ at $20 \mathrm{kHz}$ spinning speed, d) methyl and methine region of [V(acac) $\left.)_{3}\right]$ at $15 \mathrm{kHz}$ spinning speed, and e) $\left[\mathrm{Co}(\mathrm{acac})_{3}\right]$ at $9 \mathrm{kHz}$ spinning speed, using the parameters in Table 1. 
Table S8. Calculated principal values of the nuclear shielding tensors ( $\mathrm{ppm}$ ) ordered according to $\sigma_{33}>\sigma_{22}>\sigma_{11}$. The corresponding principal values of the experimentally equivalent nuclei have been averaged over.

\begin{tabular}{|c|c|c|c|c|}
\hline \multirow[b]{2}{*}{ System } & \multirow[b]{2}{*}{ Group } & \multicolumn{3}{|c|}{ Principal values of ${ }^{13} \mathrm{C}$ shielding tensor (ppm) } \\
\hline & & $\sigma_{11}$ & $\sigma_{22}$ & $\sigma_{33}$ \\
\hline \multirow[t]{3}{*}{$\mathrm{VO}(\mathrm{acac})_{2}$} & $\mathrm{CO}$ & -986 & -580 & -425 \\
\hline & $\mathbf{C H}$ & -311 & 33 & 52 \\
\hline & $\mathrm{CH}_{3}$ & 230 & 263 & 288 \\
\hline \multirow[t]{3}{*}{$\mathrm{V}(\mathbf{a c a c})_{3}$} & $\mathrm{CO}$ & -1133 & -951 & -396 \\
\hline & $\mathrm{CH}$ & -188 & 284 & 446 \\
\hline & $\mathrm{CH}_{3}$ & 364 & 437 & 484 \\
\hline \multirow[t]{3}{*}{$\mathrm{Ni}(\operatorname{acac})_{2}\left(\mathrm{H}_{2} \mathrm{O}\right)_{2}$} & $\mathrm{CO}$ & -703 & 140 & 486 \\
\hline & $\mathrm{CH}$ & -492 & 140 & 272 \\
\hline & $\mathrm{CH}_{3}$ & -1158 & -761 & -717 \\
\hline \multirow[t]{3}{*}{$\mathrm{Cu}(\mathrm{acac})_{2}$} & $\mathrm{CO}$ & -369 & 35 & 452 \\
\hline & $\mathrm{CH}$ & 42 & 191 & 464 \\
\hline & $\mathrm{CH}_{3}$ & -1112 & -963 & -820 \\
\hline
\end{tabular}


Table S9. Physical contributions (in ppm) to the calculated isotropic ${ }^{13} \mathrm{C}$ shielding constants for the four compounds according to the break-down of Ref. 1 .

\begin{tabular}{|c|c|c|c|c|c|}
\hline Group & Term $^{a}$ & [VO(acac) $\left.)_{2}\right]$ & {$\left[\mathrm{V}(\text { acac })_{3}\right]$} & {$\left[\mathrm{Ni}(\operatorname{acac})_{2}\left(\mathrm{H}_{2} \mathrm{O}\right)_{2}\right]$} & {$\left[\mathrm{Cu}(\mathrm{acac})_{2}\right]$} \\
\hline \multirow[t]{11}{*}{$\mathrm{CH}_{3}$} & orb & 161.1 & 161.1 & 160.0 & 160.5 \\
\hline & 1 & 101.2 & 321.0 & -924.5 & -1041.7 \\
\hline & 2 & 0.0 & 0.1 & -0.9 & 0.0 \\
\hline & 3 & 0.0 & 0.0 & 0.0 & 0.0 \\
\hline & 4 & 0.0 & 0.0 & 0.0 & 0.0 \\
\hline & 5 & 0.0 & 0.0 & 0.0 & 0.0 \\
\hline & 6 & -1.8 & -52.8 & -110.1 & -89.4 \\
\hline & 7 & 0.0 & 0.0 & -0.1 & 0.0 \\
\hline & 8 & 0.0 & -0.4 & -0.2 & 0.0 \\
\hline & 9 & -0.2 & -0.5 & -1.5 & 5.8 \\
\hline & tot & 260.3 & 428.5 & -878.3 & -964.7 \\
\hline \multirow[t]{11}{*}{$\mathrm{CO}$} & orb & -10.0 & -3.6 & -10.6 & -8.3 \\
\hline & 1 & -664.8 & -986.5 & -9.7 & 32.2 \\
\hline & 2 & 0.0 & 0.0 & -1.5 & 0.0 \\
\hline & 3 & 0.0 & 0.0 & 0.0 & 0.0 \\
\hline & 4 & 0.0 & 0.0 & 0.0 & 0.0 \\
\hline & 5 & 0.0 & 0.0 & 0.0 & 0.0 \\
\hline & 6 & 12.1 & 162.3 & -1.2 & 2.8 \\
\hline & 7 & 0.0 & 0.0 & -0.2 & 0.0 \\
\hline & 8 & 0.0 & 1.3 & 0.0 & 0.0 \\
\hline & 9 & -0.6 & -0.3 & -2.5 & 12.8 \\
\hline & tot & -663.3 & -826.8 & -25.6 & 39.6 \\
\hline \multirow[t]{11}{*}{$\mathrm{CH}$} & orb & 82.2 & 91.2 & 86.2 & 85.3 \\
\hline & 1 & -160.0 & 113.1 & -98.4 & 128.0 \\
\hline & 2 & 0.0 & 1.7 & -1.0 & 0.0 \\
\hline & 3 & 0.0 & 0.0 & 0.0 & 0.0 \\
\hline & 4 & 0.0 & 0.0 & 0.0 & 0.0 \\
\hline & 5 & 0.0 & 0.0 & 0.0 & 0.0 \\
\hline & 6 & 2.9 & -18.6 & -11.7 & 11.0 \\
\hline & 7 & 0.0 & -0.3 & -0.1 & 0.0 \\
\hline & 8 & 0.0 & -0.2 & 0.0 & 0.0 \\
\hline & 9 & -0.6 & -6.6 & -1.7 & 7.9 \\
\hline & tot & -75.5 & 180.4 & -26.7 & 232.2 \\
\hline
\end{tabular}

${ }^{a}$ See Table S1 for the explanation of the different terms. Terms 3 and 4 are presently merged to terms 1 and 2, respectively, and term 5 does not contribute to the isotropic shielding constant. 


\section{S2. X-Ray Crystallography}

The data were collected at 100(1)K on a Synergy, Dualflex, AtlasS2 diffractometer using $\mathrm{CuK \alpha}$ radiation $\left(\lambda=1.54184 \AA\right.$ ) and the CrysAlis PRO suite (ver. 1.171.40.29a). ${ }^{3}$ Using SHELXLE ${ }^{4}$ and Olex $2^{5}$ the structure was solved by dual space methods $\left(\right.$ SHELXT $\left.^{6}\right)$ and refined on $F^{2}$ using all the reflections (SHELXL-2018/37). All the non-hydrogen atoms were refined using anisotropic atomic displacement parameters and hydrogen atoms were inserted at calculated positions using a riding model. The crystal was found to be pseudomerohedrally twinned by rotation about the $\left(\begin{array}{lll}0 & 0 & 1\end{array}\right)$ reciprocal axis (scales: $0.565(2), 0.435(2))$. A number of polymorphs of [V(acac) 3$]$ are known; ${ }^{8}$ with the phase observed apparently dependent on the crystallisation solvent and the data collection temperature. The current example appears to be the same as that reported by Sanz-Ruiz et $a l^{9}$ at room temperature, although no twinning was reported in that case and the current refinement is significantly better. Crystal data, data collection and structure refinement details are summarised in Table S4, selected bond lengths and angles in Table S5.

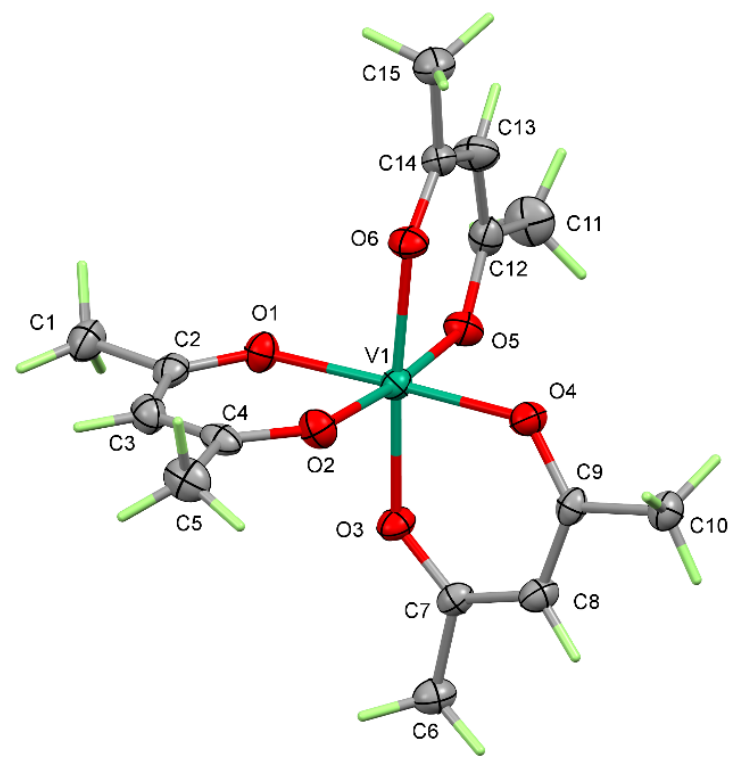

Fig. S2. Perspective diagram of $\left[\mathrm{V}(\mathrm{acac})_{3}\right]$ showing $50 \%$ probability ellipsoids. Hydrogen atoms shown as rods. 
Table S10. Crystallographic data and structure refinement for [V(acac) 3$]$.

\begin{tabular}{|c|c|}
\hline Identification code & vacac \\
\hline Empirical formula & $\mathrm{C}_{15} \mathrm{H}_{21} \mathrm{O}_{6} \mathrm{~V}$ \\
\hline Formula weight & 348.26 \\
\hline Temperature/K & $100.00(10)$ \\
\hline Crystal system & monoclinic \\
\hline Space group & $\mathrm{P} 2{ }_{1} / \mathrm{n}$ \\
\hline $\mathrm{a} / \AA$ & $7.9785(3)$ \\
\hline $\mathrm{b} / \AA$ & $12.9974(5)$ \\
\hline $\mathrm{c} / \AA ̊$ & $15.9540(6)$ \\
\hline$\alpha /{ }^{\circ}$ & 90 \\
\hline$\beta /{ }^{\circ}$ & $90.022(4)$ \\
\hline$\gamma /{ }^{\circ}$ & 90 \\
\hline Volume $/ \AA^{3}$ & $1654.42(11)$ \\
\hline $\mathrm{Z}$ & 4 \\
\hline$\rho_{\text {calcg }} / \mathrm{cm}^{3}$ & 1.398 \\
\hline$\mu / \mathrm{mm}^{-1}$ & 5.243 \\
\hline $\mathrm{F}(000)$ & 728.0 \\
\hline Crystal size $/ \mathrm{mm}^{3}$ & $0.121 \times 0.087 \times 0.035$ \\
\hline Radiation & $\mathrm{CuK} \alpha(\lambda=1.54184)$ \\
\hline $2 \theta$ range for data collection ${ }^{\circ}$ & 8.776 to 152.468 \\
\hline Index ranges & $-9 \leq \mathrm{h} \leq 5,-16 \leq \mathrm{k} \leq 15,-19 \leq 1 \leq 18$ \\
\hline Reflections collected & 7657 \\
\hline Independent reflections & $3338\left[R_{\text {int }}=0.0353, R_{\text {sigma }}=0.0410\right]$ \\
\hline Data/restraints/parameters & $3338 / 0 / 206$ \\
\hline Goodness-of-fit on $\mathrm{F}^{2}$ & 1.064 \\
\hline Final $R$ indexes $[\mathrm{I}>=2 \sigma(\mathrm{I})]$ & $\mathrm{R} 1=0.0465, \mathrm{wR} 2=0.1274$ \\
\hline Final $\mathrm{R}$ indexes [all data] & $\mathrm{R} 1=0.0474, \mathrm{wR} 2=0.1291$ \\
\hline Largest diff. peak/hole / e $\AA^{-3}$ & $0.43 /-0.68$ \\
\hline
\end{tabular}


Table S11. Selected Geometric parameters $\left(\AA,^{\circ}\right)$ for [V(acac $\left.)_{3}\right]$.

\begin{tabular}{llll}
\hline \multicolumn{4}{l}{ Bond distancers $[\AA \AA \mathbf{l}$} \\
$\mathrm{V} 1-\mathrm{O} 1$ & $1.991(2)$ & $\mathrm{V} 1-\mathrm{O} 4$ & $1.986(2)$ \\
$\mathrm{V} 1-\mathrm{O} 2$ & $1.990(2)$ & $\mathrm{V} 1-\mathrm{O} 5$ & $2.001(2)$ \\
$\mathrm{V} 1-\mathrm{O} 3$ & $1.989(2)$ & $\mathrm{V} 1-\mathrm{O} 6$ & $2.009(3)$ \\
\hline Bond angles [] & & \\
\hline $\mathrm{O} 1-\mathrm{V} 1-\mathrm{O} 5$ & $87.73(9)$ & $\mathrm{O} 3-\mathrm{V} 1-\mathrm{O} 6$ & $175.19(9)$ \\
$\mathrm{O} 1-\mathrm{V} 1-\mathrm{O} 6$ & $92.62(10)$ & $\mathrm{O} 4-\mathrm{V} 1-\mathrm{O} 1$ & $178.37(9)$ \\
$\mathrm{O} 2-\mathrm{V} 1-\mathrm{O} 1$ & $87.52(9)$ & $\mathrm{O} 4-\mathrm{V} 1-\mathrm{O} 2$ & $91.03(10)$ \\
$\mathrm{O} 2-\mathrm{V} 1-\mathrm{O} 5$ & $174.36(10)$ & $\mathrm{O} 4-\mathrm{V} 1-\mathrm{O} 3$ & $88.26(10)$ \\
$\mathrm{O} 2-\mathrm{V} 1-\mathrm{O} 6$ & $89.87(10)$ & $\mathrm{O} 4-\mathrm{V} 1-\mathrm{O} 5$ & $93.75(9)$ \\
$\mathrm{O} 3-\mathrm{V} 1-\mathrm{O} 1$ & $91.09(10)$ & $\mathrm{O} 4-\mathrm{V} 1-\mathrm{O} 6$ & $88.11(10)$ \\
$\mathrm{O} 3-\mathrm{V} 1-\mathrm{O} 2$ & $93.33(10)$ & $\mathrm{O} 5-\mathrm{V} 1-\mathrm{O} 6$ & $87.30(10)$ \\
$\mathrm{O} 3-\mathrm{V} 1-\mathrm{O} 5$ & $89.81(10)$ & & \\
\hline
\end{tabular}




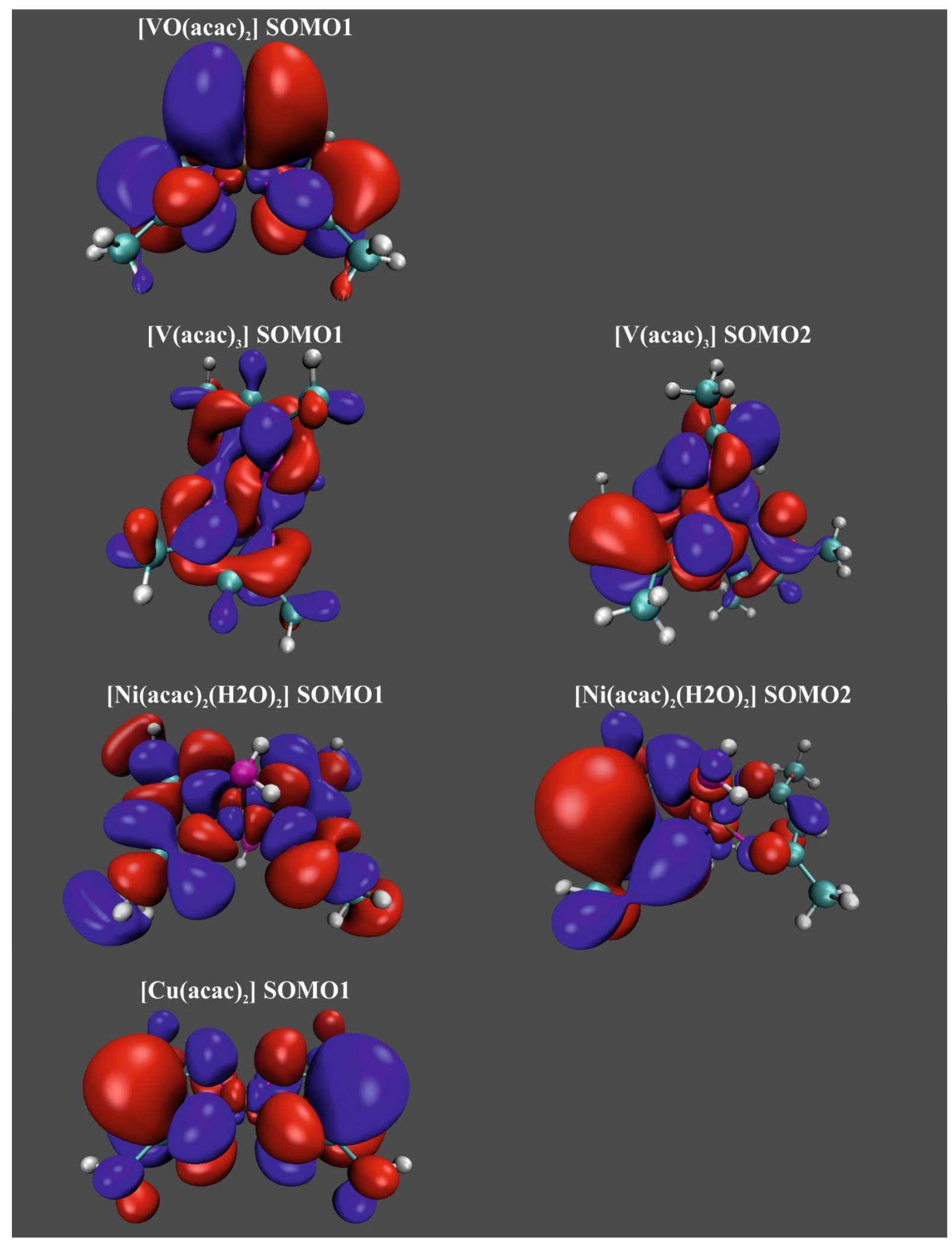

Fig. S3. Singly Occupied Molecular Orbitals (SOMOs) for [VO(acac) $)_{2}$, [V(acac) 3$]$, $\left[\mathrm{Ni}(\mathrm{acac})_{2}\left(\mathrm{H}_{2} \mathrm{O}\right)_{2}\right]$, and $\left[\mathrm{Cu}(\mathrm{acac})_{2}\right]$. 


\section{References}

1. T. O. Pennanen and J. Vaara, Phys. Rev. Lett., 2008, 100, 133002.

2. S. A. Rouf, V. B. Jakobsen, J. Mareš, N. D. Jensen, C. J. McKenzie, J. Vaara and U. G. Nielsen, Solid State Nucl. Magn. Reson., 2017, 87, 29-37.

3. , 1.171.40.29a edn., 2018, pp. Rigaku Oxford Diffraction, Rigaku Corporation, Oxford, UK.

4. C. B. Hübschle, G. M. Sheldrick and B. Dittrich, J. Appl. Cryst., 2011, 44, 1281-1284.

5. O. V. Dolomanov, L. J. Bourhis, R. J. Gildea, J. A. Howard and H. Puschmann, J.Appl. Cryst., 2009, 42, 339-341.

6. G. M. Sheldrick, Acta Cryst. A, 2015, A71, 3-8.

7. G. M. Sheldrick, Acta Crys. C, 2015, C71, 3-8.

8. E. Arslan, R. A. Lalancette and I. Bernal, Struc. Chem., 2017, 28, 201-212.

9. F. Sanz-Ruiz, S. Martínez-Carrera and S. García-Blanco, An. R. Soc. Esp. Fis. Quim., Ser. A, 1970, 66, 309. 